\title{
ANÁLISIS ESPACIAL DE LOS DETERMINANTES SOCIOECONÓMICOS DE LA SALUD EN EL GRAN RESISTENCIA
}

\section{SPATIAL ANALYSIS OF SOCIO-ECONOMIC DETERMINANTS OF HEALTH IN THE GRAN RESISTENCIA}

\author{
Dra. Blanca Elizabeth Ponce \\ Dto. de Geografía. Facultad de Humanidades. UNNE \\ Prof. Auxiliar en Geografía y Sociedad \\ IIGHI-CONICET-UNNE. Becaria del CONICET \\ E-mail: blancae ponce@yahoo.com.ar \\ Dra. María Alejandra Fantín \\ Dto.de Geografía. Facultad de Humanidades. UNNE \\ Prof.Titular en Geografía y Sociedad \\ IIGHI-CONICET-UNNE. Investigadora Independiente del CONICET \\ E-mail: mafantin@gmail.com \\ Dra. Carola Leticia Bertone \\ CIECS - CONICET -UNC. Becaria del CONICET \\ E-mail: bertonecarol@hotmail.com
}

\begin{abstract}
RESUMEN
Las condiciones en que viven las personas influyen de manera decisiva en su salud, por lo que es necesario actuar en todos los sectores para promover el bienestar. Podemos distinguir una serie de determinantes que influyen en las condiciones de salud, entre los cuales, se encuentran: los sociales, económicos, políticos, culturales y medioambientales.

Dentro de este marco, la presente investigación tiene por objetivo realizar una clasificación y caracterización de las diferencias socio-espaciales del Gran Resistencia. Para ello, aplicamos el análisis de conglomerados a un conjunto de variables vinculadas con los determinantes socioeconómicos de la salud. Además, esta clasificación se realizó considerando las áreas de influencia de los Centros de Salud, con el fin de caracterizar la demanda existente en ellos. Nuestra principal fuente de información fue el Censo Nacional de Población, Hogar y Vivienda del año 2001.
\end{abstract}

PALABRAS CLAVES: Determinantes Socioeconómicos; Salud; Conglomerados; Análisis Espacial.

\section{ABSTRACT}

The conditions in which people live influence decisively in their health, so it is necessary to act in all sectors to promote the wellness. We can distinguish a series of determinants that influence health conditions, between which are: the social, economic, political, cultural and environmental.

Within this framework, this research aims to realize a classification and characterization of the differences socio-spatial of the Gran Resistencia. For this, we apply cluster analysis to a set of variables linked with the socioeconomic determinants of the health. Besides, this classification was realized considering the areas of influence of the Centers of Health, in order to characterize the existing demand in them. Our main source of information was the "Censo Nacional de Población, Hogar y Vivienda" of the year 2001.

KEY WORDS: Socioeconomic determinants; Health; Clusters; Spatial Analysis.

Publicado en formato digital: Dras. Blanca Elizabeth Ponce, María Alejandra Fantín y Carola Leticia Bertone. ANÁLISIS ESPACIAL DE LOS DETERMINANTES SOCIOECONÓMICOS DE LA SALUD EN EL GRAN RESISTENCIA. Revista Geográfica Digital. IGUNNE. Facultad de Humanidades. UNNE. Año 11. № 22. Julio Diciembre. 2014. ISSN 1668-5180 Resistencia, Chaco.

En: http://hum.unne.edu.ar/revistas/geoweb/default.htm 
Revista Geográfica Digital. IGUNNE. Facultad de Humanidades. UNNE. Año 11. № 22.

Julio - Diciembre 2014. ISSN 1668-5180 Resistencia, Chaco

\section{Introducción}

Durante siglos la salud fue entendida como "ausencia de enfermedad", hasta que en 1946 la Organización Mundial de la Salud ${ }^{1}$ modifica el concepto y pasa a definirla dscomo "un estado de completo bienestar físico, mental y social, y no sólo la ausencia de enfermedad". Definición que tuvo gran repercusión y en nuestros días es una de las más conocidas y difundidas.

Esta definición supuso un cambio sustancial en la concepción de la salud, en primer lugar por su carácter positivo, en tanto que considera la salud no sólo como la ausencia de enfermedades, sino como un estado óptimo positivo, o "completo bienestar". Por otro lado, al incorporar el factor "social" como determinante de la salud, supuso un cambio substancial porque la salud dejó de depender exclusivamente del ámbito sanitario para integrarse también en el mundo social.

Hoy sabemos que las condiciones en que viven las personas influyen de manera decisiva en su salud, por lo que es necesario actuar en todos los sectores para promover el bienestar, tal como se destaca en la Declaración de Alma Ata².

Podemos distinguir una serie de determinantes que influyen en las condiciones de salud de las personas, entre los cuales, se encuentran: los sociales, económicos, políticos, culturales y medioambientales.

Sin embargo, no todos los determinantes revisten la misma importancia. Los más importantes son los que dan lugar a una estratificación dentro de la sociedad (determinantes estructurales), como la distribución de ingresos o la discriminación por factores como género, etnia o discapacidad, y las estructuras políticas y de gobernanza que refuerzan las desigualdades en el poder económico en lugar de reducirlas. Estos determinantes establecen un conjunto de posiciones socioeconómicas dentro de jerarquías de poder, prestigio y acceso a los recursos y configuran el estado de salud y los resultados de salud de cada individuo a través de su repercusión sobre determinantes intermedios, como las condiciones de vida, las circunstancias psicosociales, factores conductuales o biológicos y el propio sistema de salud (OMS, 2011).

Dentro de este marco, la presente investigación tiene por objetivo realizar una clasificación y caracterización de las diferencias socio-espaciales del Gran Resistencia, mediante la aplicación del análisis de conglomerados a un conjunto de variables que se encuentran vinculadas con los determinantes socioeconómicos de la salud. Asimismo, esta clasificación espacial se realizó considerando las áreas de influencia de los Centros de Salud (Áreas Programáticas), con el fin de caracterizar la demanda existente en ellos.

Para cumplir con este objetivo, nuestra principal fuente de información fue el Censo Nacional de Población, Hogar y Vivienda del año 2001, siendo hasta el momento la única información censal disponible con mayor nivel de desagregación. Consideramos estos datos bajo el supuesto que las características estructurales de los hogares no han sufrido grandes transformaciones en los últimos años.

A partir del programa Redatam $+\mathrm{SP}^{3}$, se obtuvieron tabulados especiales, a nivel de nivel de fracción y radio censal. Al no existir una correlación espacial entre las Áreas Programáticas y las divisiones censales, se debió identificar previamente las fracciones y radios censales que conforman cada una de las áreas; dicha tarea posibilitó la confección de una base de datos acorde a nuestra investigación a partir del procesamiento de los datos con el programa SPSS ${ }^{4}$.

Las variables seleccionadas fueron: niños menores de 5 años; población mayor de 65 años; índice de masculinidad; población de 18 años y más que no saben leer ni escribir; población de 25 años y más con estudios terciarios y universitarios completos; población sin obra social; hogares sin agua dentro de la vivienda y el terreno; hogares con inodoro sin descarga de agua y hogares sin inodoro; hogares con CALMAT I; hogares con viviendas deficitarias; hogares con hacinamiento por cuarto (más de 3 personas); hogares con paredes de adobe, madera, chapa y cartón; hogares con piso de tierra; hogares con jefes y cónyuge desocupados; población mayor de 65 años sin jubilación; hogares sin transporte público; hogares sin alumbrado público y hogares sin calles pavimentadas.

Publicado en formato digital: Dras. Blanca Elizabeth Ponce, María Alejandra Fantín y Carola Leticia Bertone. ANÁLISIS ESPACIAL DE LOS DETERMINANTES SOCIOECONÓMICOS DE LA SALUD EN EL GRAN RESISTENCIA. Revista Geográfica Digital. IGUNNE. Facultad de Humanidades. UNNE. Año 11. № 22. Julio Diciembre. 2014. ISSN 1668-5180 Resistencia, Chaco.

En: http://hum.unne.edu.ar/revistas/geoweb/default.htm 
Por otra parte, la base cartográfica de las Áreas Programáticas que conforman el Gran Resistencia fue digitalizada y transformada en formato vectorial, a través del programa CartaLinx $x^{5}$. Finalmente, se utilizó el programa $A r c G / S^{6}$, a partir del cual se representó los datos georreferenciados sobre una cartografía y se analizaron las características y patrones de distribución de los datos.

\section{Marco Espacial de la Investigación}

El marco espacial de esta investigación lo constituye el Gran Resistencia ${ }^{7}$. Dicho aglomerado se ubica geográficamente en el sureste de la provincia del Chaco (República Argentina), en el departamento San Fernando (Mapa $N^{\circ} 1$ ). Está constituido por cuatro ciudades quienes debido a su continuidad geográfica están funcionalmente articuladas: Resistencia (capital de la provincia), Barranqueras, Puerto Vilelas y Fontana.

\section{Mapa $\mathbf{N}^{\circ} \mathbf{1}$}

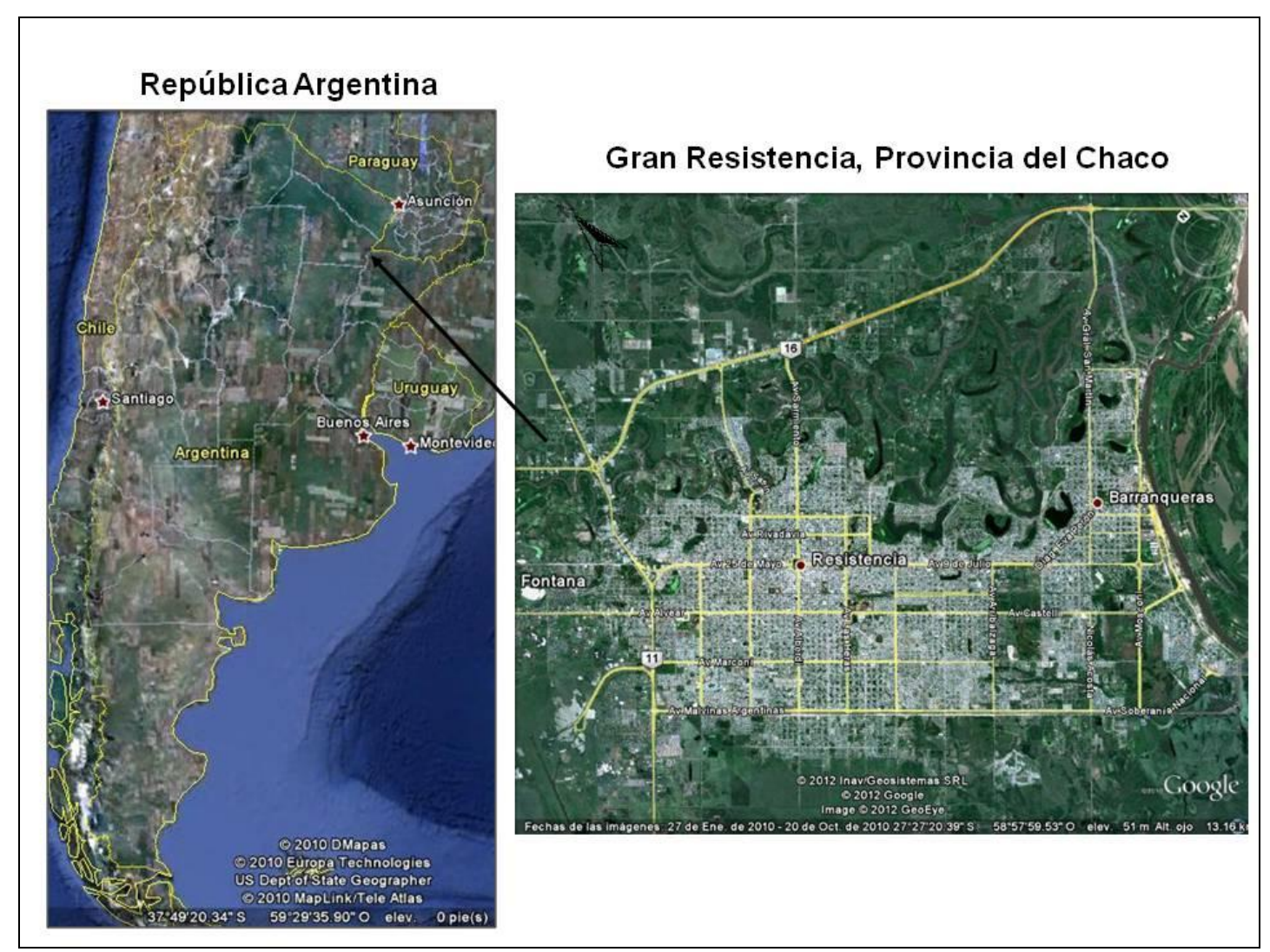

Fuente: Elaboración propia, en base a la información de Google Earth (2010 y 2012).

A modo de organización, el Ministerio de Salud Pública de la Provincia del Chaco, ha dividido el territorio en Áreas Programáticas, en las cuales se desarrollan todas las acciones de salud, tendientes a asegurar la cobertura de toda la población bajo su responsabilidad. Además, tienen la función de facilitar a las personas una red de complejidades crecientes, que les permitan acceder al máximo nivel que la provincia o el país puedan ofrecer.

En la actualidad existen 39 Centros de Salud con un nivel de complejidad III, que ofrecen servicios de clínica médica, pediatría, ginecología y odontología. Al mismo tiempo, coexisten 3 subcentros con un nivel de complejidad II: San Pedro Pescado, Las Lomitas y Ciudad de los Milagros. En todos ellos, las

Publicado en formato digital: Dras. Blanca Elizabeth Ponce, María Alejandra Fantín y Carola Leticia Bertone. ANÁLISIS ESPACIAL DE LOS DETERMINANTES SOCIOECONÓMICOS DE LA SALUD EN EL GRAN RESISTENCIA. Revista Geográfica Digital. IGUNNE. Facultad de Humanidades. UNNE. Año 11. № 22. Julio Diciembre. 2014. ISSN 1668-5180 Resistencia, Chaco.

En: http://hum.unne.edu.ar/revistas/geoweb/default.htm 
modalidades de atención son a través de la demanda espontánea o la entrega de turnos programados durante la mañana y la tarde (Mapa $\mathrm{N}^{\circ} 2$ ).

En los últimos años el Gran Resistencia ha experimentado un importante crecimiento demográfico, por lo cual, los dos hospitales públicos ${ }^{8}$ existentes no logran cubrir todas las necesidades de una demanda en constante crecimiento.

Por esta razón, el Ministerio de Salud Pública de la Provincia del Chaco ha implementado políticas para fomentar la asistencia de las personas a los centros de salud barriales. Para ello, se han convertido a cuatro de éstos en Centros Regionales de Referencia (CRR), con un nivel de complejidad IV, los cuales funcionan las 24 horas del día y tienen por fin descentralizar la atención brindada por los hospitales.

\section{Mapa $\mathbf{N}^{\circ} 2$}

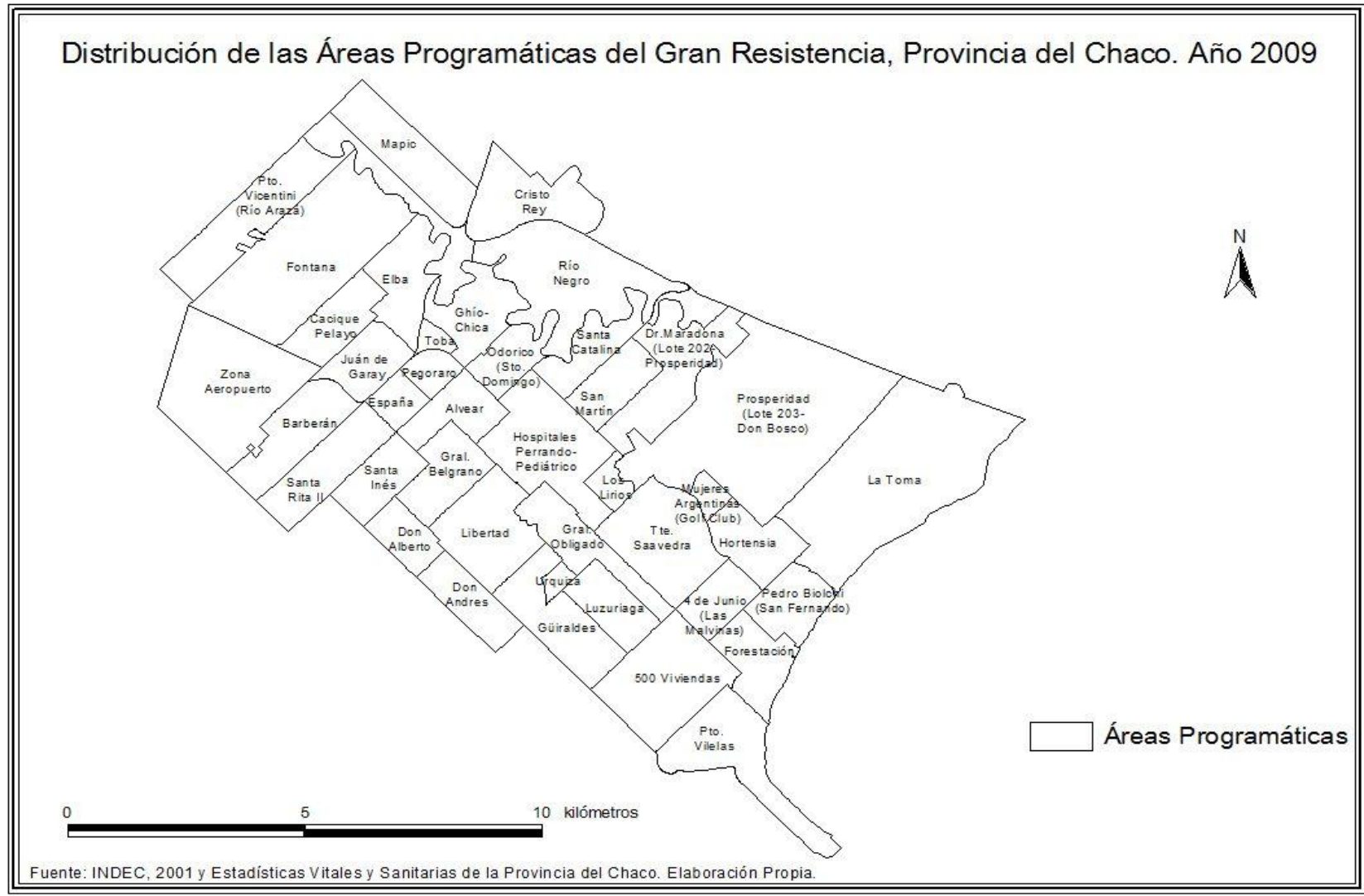

Publicado en formato digital: Dras. Blanca Elizabeth Ponce, María Alejandra Fantín y Carola Leticia Bertone. ANÁLISIS ESPACIAL DE LOS DETERMINANTES SOCIOECONÓMICOS DE LA SALUD EN EL GRAN RESISTENCIA. Revista Geográfica Digital. IGUNNE. Facultad de Humanidades. UNNE. Año 11. № 22. Julio Diciembre. 2014. ISSN 1668-5180 Resistencia, Chaco.

En: http://hum.unne.edu.ar/revistas/geoweb/default.htm 
Esquema $\mathbf{N}^{\circ} 1$

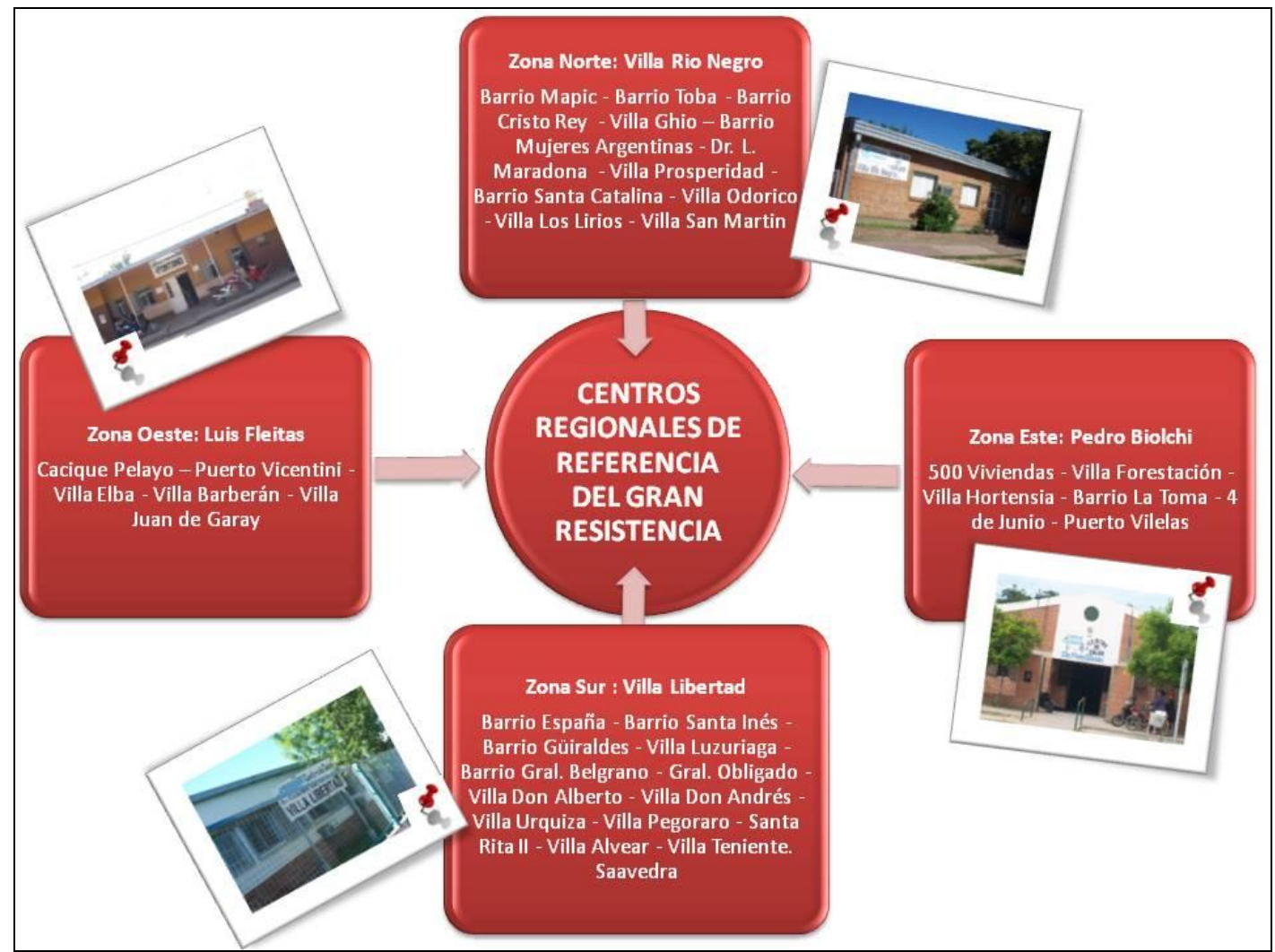

Fuente: Elaboración propia en base a los datos de la Dirección de Estadísticas Sanitarias del Ministerio de Salud Pública de la Provincia del Chaco (2010).

Cada uno de los CRR, si bien tienen su propia área de influencia, nuclean a varios centros de salud barriales, con sus propias áreas programáticas, dividiendo al territorio del Gran Resistencia en cuatro zonas: norte, sur, este y oeste. (Esquema $\mathrm{N}^{\circ} 1$ )

Entre los servicios que ofrecen podemos mencionar: Clínica Médica; Pediatría; Ginecología; Odontología; Salud Mental; Rayos X; Ecografía; Extracciones para laboratorios; Servicio social; Kinesiología; Enfermería; Servicio de Guardias las 24hs.

\section{Factores Socioeconómicos de la Salud}

La desigualdad social en salud se refiere a las distintas oportunidades y recursos relacionados con la salud que tienen las personas en función de su clase social, sexo, territorio o etnia, lo que se plasma en una peor salud en los colectivos socialmente menos favorecidos (Borrell y Artazcoz, 2008).

Existen distintos modelos para explicar los determinantes de las desigualdades en salud, uno de los primeros y más influyentes fue el de Lalonde en 1974, quien identificó como determinantes claves a los estilos de vida, el ambiente, la biología humana y los servicios de salud, en un enfoque que planteaba explícitamente que la salud es más que un sistema de atención. Este mismo autor destacó la discordancia entre esta situación y la distribución de recursos y los esfuerzos sociales asignados a los diferentes determinantes. Desde esa fecha se ha ido aprendiendo mucho más, en particular sobre los mecanismos en que los factores sociales afectan a la salud y la equidad, lo que ha permitido expandir este marco básico (Frenz, 2005).

Posteriormente surgen otras propuestas conceptuales, que al interaccionar con los identificados por Lalonde en particular las condiciones sociales, quedan diagramadas en un modelo planteado por

Publicado en formato digital: Dras. Blanca Elizabeth Ponce, María Alejandra Fantín y Carola Leticia Bertone. ANÁLISIS ESPACIAL DE LOS DETERMINANTES SOCIOECONÓMICOS DE LA SALUD EN EL GRAN RESISTENCIA. Revista Geográfica Digital. IGUNNE. Facultad de Humanidades. UNNE. Año 11. № 22. Julio Diciembre. 2014. ISSN 1668-5180 Resistencia, Chaco.

En: http://hum.unne.edu.ar/revistas/geoweb/default.htm 
Dahlgren y Whitehead y adoptado por Acheson (1998), en su informe sobre desigualdades en salud en Gran Bretaña. Este modelo presenta a los principales determinantes de la salud como capas de influencia (Figura $N^{\circ} 1$ ). En el centro se encuentra el individuo y los factores constitucionales que afectan a su salud pero que no son cambiables. A su alrededor se encuentran las capas que se refieren a determinantes posibles de modificar, comenzando por los estilos de vida individuales, objeto desde hace décadas de los esfuerzos de promoción en salud. Pero los individuos y sus conductas son influenciados por su comunidad y las redes sociales, las que pueden sostener o no a la salud de los individuos; hecho que si se ignora dificulta la adopción de conductas saludables. Los determinantes considerados más amplios o profundos, en cuanto a su influencia, tienen que ver con las condiciones de vida y trabajo, alimentos y acceso a servicios básicos, además de las condiciones socioeconómicas, culturales y ambientales, representadas en la capa más externa. El modelo intenta representar además las interacciones entre los factores (Frenz, 2005).

Figura $\mathbf{N}^{\circ} 1$

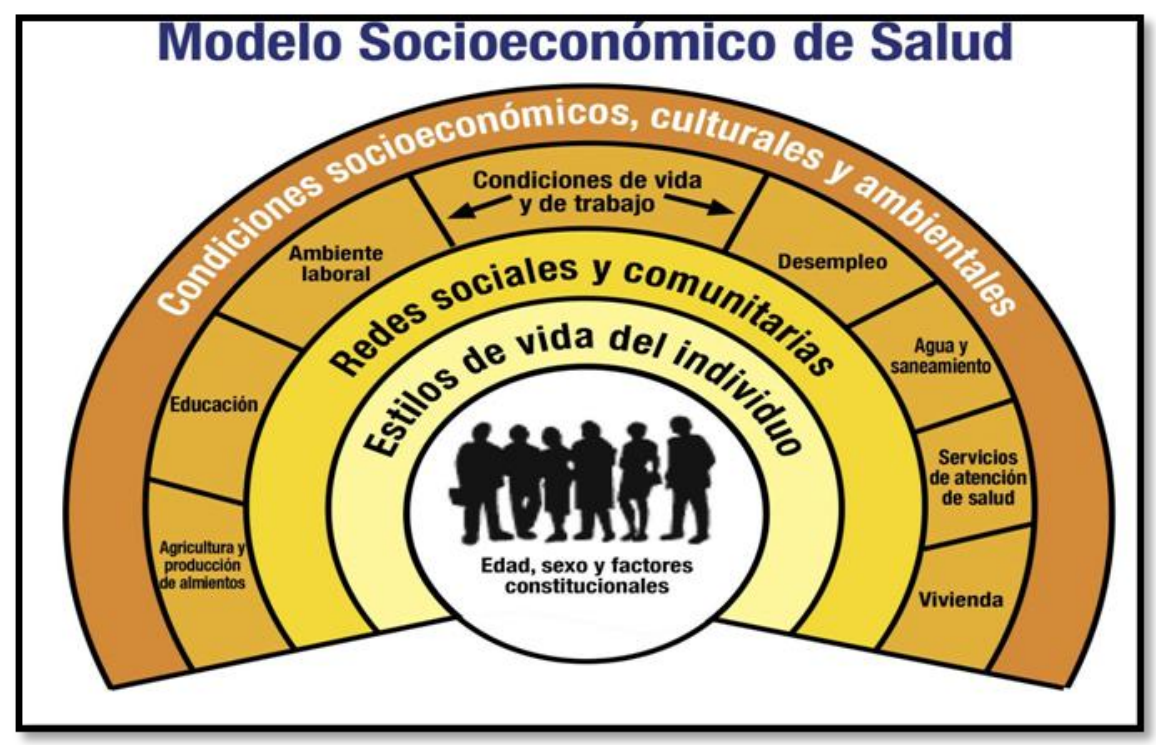

Fuente: Modelo planteado por Dahlgren y Whitehead ("Policies and strategies to promote social equity in health. Stockholm: Institute of Futures Studies, 1991.") y adoptado por Acheson (1998) en su trabajo "Independent inquiry into inequalities in health. The Stationary Office."

Construyendo sobre los modelos anteriores, intentando aclarar aún más los mecanismos por los cuales los determinantes sociales generan inequidades en salud y develando la relación entre los principales determinantes, la Comisión sobre Determinantes Sociales de la Salud plantea un marco conceptual para actuar sobre ellos. Según Borrell y Artazcoz (2008), contiene los siguientes elementos:

a) Determinantes estructurales de las desigualdades de la salud.

$\checkmark$ El contexto socioeconómico y político: se refiere a factores estructurales del sistema social que afectan de forma significativa a la estructura social. Los principales elementos que consideran son: el gobierno; las políticas macroeconómicas; las políticas sociales que afectan al mercado de trabajo; las políticas públicas que inciden en el acceso de la población a los distintos servicios y los valores sociales y culturales.

$\checkmark$ La posición socioeconómica: incluye determinantes estructurales de las de desigualdades en salud, como los distintos ejes de desigualdad de la estructura social, como por ejemplo la clase social, la posición socioeconómica, el género y la etnia. Estos ejes determinan las oportunidades de tener una buena salud y ponen de manifiesto la existencia de desigualdades en salud debidas a las jerarquías de poder o de acceso a los recursos.

Publicado en formato digital: Dras. Blanca Elizabeth Ponce, María Alejandra Fantín y Carola Leticia Bertone. ANÁLISIS ESPACIAL DE LOS DETERMINANTES SOCIOECONÓMICOS DE LA SALUD EN EL GRAN RESISTENCIA. Revista Geográfica Digital. IGUNNE. Facultad de Humanidades. UNNE. Año 11. № 22. Julio Diciembre. 2014. ISSN 1668-5180 Resistencia, Chaco.

En: http://hum.unne.edu.ar/revistas/geoweb/default.htm 
b) Determinantes intermedios o factores intermediarios: la estructura social determina desigualdades en los factores intermediarios, los cuales, a su vez, determinan las desigualdades en salud. Estos factores son:

$\checkmark$ Las circunstancias materiales: como la vivienda, el nivel de ingresos, las condiciones de trabajo o el barrio de residencia.

$\checkmark$ Las circunstancias psicosociales: como la falta de apoyo social, las situaciones de estrés (acontecimientos vitales negativos), etc.

$\checkmark$ Los factores conductuales y biológicos: como los estilos de vida que dañan la salud.

$\checkmark$ El sistema de salud: pues aunque los servicios sanitarios contribuyen muy poco a las desigualdades en salud, el menor acceso a ellos y su menor calidad para las personas de clases sociales menos favorecidas es una vulneración de los derechos humanos.

El enfoque basado en los determinantes sociales exige actuar de manera coordinada y coherente en los sectores de la sociedad que influyen en los determinantes estructurales, a fin de mejorar la salud y reducir las inequidades. A su vez, hoy en día se sabe que una mejor salud contribuye a otras prioridades sociales importantes, como mayor bienestar, educación, cohesión social, protección ambiental, mayor productividad y desarrollo económico. En este "círculo virtuoso", las mejoras en la salud y sus determinantes se retroalimentan y se ofrecen beneficios mutuos (OMS, 2011).

\section{Las Dimensiones de Análisis}

No todos los determinantes socioeconómicos de la salud revisten la misma importancia. Los más importantes son los que dan lugar a una estratificación dentro de la sociedad (determinantes estructurales), como la distribución de ingresos o la discriminación por factores como género, etnia o discapacidad, y las estructuras políticas y de gobernanza que refuerzan las desigualdades en el poder económico en lugar de reducirlas. Estos determinantes establecen un conjunto de posiciones socioeconómicas dentro de jerarquías de poder, prestigio y acceso a los recursos y configuran el estado de salud y los resultados de salud de cada individuo a través de su repercusión sobre determinantes intermedios, como las condiciones de vida, las circunstancias psicosociales, factores conductuales o biológicos y el propio sistema de salud (OMS, 2011).

En esta oportunidad hemos seleccionado 18 variables vinculadas con los determinantes socioeconómicos de la salud. Las mismas fueron agrupadas en 6 dimensiones las cuales se describen a continuación.

\subsection{Dimensión Demográfica}

La composición de una población por edad y sexo es la variable demográfica básica para cualquier estudio de la población, ya que la misma tiene decisiva importancia por sus repercusiones en el orden social, económico y médico. Por esta razón, se ha incorporado en esta dimensión las siguientes variables: niños menores de 5 años de edad; población mayor de 65 años e índice de masculinidad".

Desde el punto de la salud, la estructura por edad determina grandes diferencias. En la infancia y juventud se manifiestan en mayor grado las enfermedades infecciosas, en contraste con las poblaciones ancianas, donde se destacan los problemas crónicos y degenerativos propios del adulto y del anciano. En las primeras, tienen especial interés la atención materna e infantil, saneamiento, inmunizaciones y fomento de la salud, mientras que en las poblaciones viejas aparecen como importantes los sistemas de diagnóstico precoz, la atención de los adultos y ancianos y la rehabilitación (Fantin, 2008). A su vez, con la edad varía la morbilidad y la incidencia de la muerte, ya que normalmente ésta afecta de forma más intensa en los primeros años de vida y en la vejez.

Por otra parte, la diferencia de sexo genera desigualdad en la esperanza de vida, en la morbilidad y la mortalidad.

Publicado en formato digital: Dras. Blanca Elizabeth Ponce, María Alejandra Fantín y Carola Leticia Bertone. ANÁLISIS ESPACIAL DE LOS DETERMINANTES SOCIOECONÓMICOS DE LA SALUD EN EL GRAN RESISTENCIA. Revista Geográfica Digital. IGUNNE. Facultad de Humanidades. UNNE. Año 11. № 22. Julio Diciembre. 2014. ISSN 1668-5180 Resistencia, Chaco.

En: http://hum.unne.edu.ar/revistas/geoweb/default.htm 
Revista Geográfica Digital. IGUNNE. Facultad de Humanidades. UNNE. Año 11. № 22. Julio - Diciembre 2014. ISSN 1668-5180 Resistencia, Chaco

\subsection{Dimensión Educación}

Esta dimensión incluye el análisis del analfabetismo y el máximo nivel de instrucción. Para ello, se consideraron las variables: población de 18 años de edad y más que no sabe leer ni escribir y población de 25 años de edad y más con estudios Universitarios y Terciarios completos ${ }^{10}$.

La educación formal e institucionalizada es un componente de la calidad de vida ${ }^{11}$. Los aspectos educativos tienen una marcada influencia en las condiciones socioeconómicas de las personas, por su estrecha relación entre el nivel de instrucción y empleo y la categoría ocupacional y remuneración. En consecuencia, a mayor nivel educativo, mayor capacidad tienen las personas para desarrollar sus potencialidades e ingresar en el mercado laboral, reforzando la cohesión social y el desarrollo para mejorar su calidad de vida. En contraposición, un menor nivel educativo se relaciona con la idea de fracaso y exclusión social, situaciones que repercuten en el incremento de las brechas sociales (Sabuda, 2008).

Por permitir entonces, tener un mejor nivel socioeconómico, la variable educación puede ser considerada como un factor determinante de la salud de las personas, ya que no sólo les permite contratar prestaciones médicas privadas, sino que también, posibilita el acceso a tratamientos y medicamentos de alto costo.

\subsection{Dimensión Salud}

Como se explicara antes, la salud de las personas presenta un fuerte gradiente social, invariablemente desfavorable a los grupos socialmente menos privilegiados. Por esta razón es importante considerar en esta dimensión a la población sin obra social ${ }^{2}$, ya que la misma refleja indirectamente no sólo la proporción de población "no contenida" por el sistema sanitario, sino también la naturaleza del proceso de inserción de cada fracción social en la estructura económica. (Boroni y otros, 2002).

Otro de los determinantes de la salud lo representa la disponibilidad de agua en la vivienda. La tenencia de este servicio básico, permite satisfacer necesidades como el consumo de agua y mantener las condiciones de higiene del hogar y sus integrantes. Su estudio se realizó a través de la variable hogares sin agua dentro de la vivienda, que surge de la conjunción de dos características: provisión de agua fuera de la vivienda pero dentro del terreno ${ }^{13}$ y provisión de agua fuera del terreno ${ }^{14}$.

El agua es un recurso indispensable para el desarrollo de la vida humana, el cual debe ser provisto de forma abundante y bajo las condiciones adecuadas. Es importante conocer no sólo su origen, sino también, las formas en que las personas acceden el dentro de su vivienda.

Con respecto a la forma de acceso en la vivienda, se considera apropiado un sistema de distribución del agua por cañerías; el mismo permite conducir el agua desde el lugar donde la vivienda se alimenta de la misma hasta los puntos de utilización. Este sistema cerrado asegura el mantenimiento de la calidad del agua, desde su provisión hasta el lugar del suministro para su uso (Aguilar, 2005).

Según Rogeaux (1993) las enfermedades relacionadas con el agua pueden dividirse en cuatro categorías:

> Propagadas por el agua: el agua actúa como vehículo de transporte pasivo del elemento patógeno. La infección se produce al beber agua 0 al ingerir alimentos contaminados. La transmisión está relacionada directamente con la calidad del agua. Enfermedades relacionadas: diarreicas, cólera, fiebre tifoidea, polio, leptospirosis, giardiasis, amebiasis, hepatitis infecciosa.

> Lavadas por el agua: son enfermedades causadas por la falta de higiene o por una higiene precaria (en particular el lavado de manos), que disminuyen con un mejor acceso al agua y con mayores cantidades de agua. Enfermedades relacionadas: diarreicas, enfermedades transmitidas por pulgas (tifus), infecciones por salmonella, sarna, anquilostomiasis, micosis, infecciones oculares (tracoma, conjuntivitis), piojos, asma.

Publicado en formato digital: Dras. Blanca Elizabeth Ponce, María Alejandra Fantín y Carola Leticia Bertone. ANÁLISIS ESPACIAL DE LOS DETERMINANTES SOCIOECONÓMICOS DE LA SALUD EN EL GRAN RESISTENCIA. Revista Geográfica Digital. IGUNNE. Facultad de Humanidades. UNNE. Año 11. № 22. Julio Diciembre. 2014. ISSN 1668-5180 Resistencia, Chaco.

En: http://hum.unne.edu.ar/revistas/geoweb/default.htm 
> Con base en el agua: en regiones endémicas, el mero contacto con aguas contaminadas por organismos (moluscos y copépodos) que actúan como huéspedes de ciertos parásitos es suficiente para contraer la infección. Enfermedades Relacionadas: esquistosomiasis, dracontiasis (gusano de Guinea).

> Provocadas por un insecto vector relacionadas con el agua: las infecciones son transmitidas por insectos que se reproducen en el agua o pican en su proximidad. Enfermedades Relacionadas: paludismo, fiebre amarilla, dengue, oncocercosis, filariasis, enfermedad del sueño.

Asimismo se incorporó a esta dimensión la variable hogares sin inodoro con descarga de agua y hogares sin inodoros ${ }^{15}$. En relación a las instalaciones sanitarias, Fantín (1999) ha manifestado que, así como el acceso a la red de agua corriente puede considerarse como un indicador del alcance de la infraestructura de servicios públicos, el hecho de que una vivienda disponga o no de inodoro con descarga de agua apunta a la capacidad "propia" de mejoras de los hogares ${ }^{16}$. Esto es importante para determinar la calidad de vida por su íntima relación con la higiene y la salud, puesto que la población tiene menos posibilidades de padecer enfermedades diarreicas si se tiene acceso a agua limpia y cuenta con buenas instalaciones sanitarias, debido a que los microbios causantes de la diarrea se transmite generalmente de persona a persona por la ruta fecal-oral ${ }^{17}$.

\subsection{Dimensión Habitacional}

La vivienda es uno de los indicadores que habitualmente se utiliza como factor calificativo de la calidad de vida, ya que forma parte de las necesidades básicas de todo individuo. En condiciones ideales, reduce al mínimo la probabilidad de enfermedad, de lesión, contribuyendo al bienestar físico, mental y social, puesto que el fin básico de la vivienda es el de cobijar frente a los elementos de la naturaleza y constituir el núcleo de vida familiar. En suma, una vivienda debe proteger contra los riesgos de salud, derivados del ambiente físico y social.

Además, la calidad del hábitat y de la vivienda contribuye a revelar las diferencias socioeconómicas y el grado con que influirán en la salud de la población. En las áreas urbanas las malas condiciones de la higiene y el hacinamiento en viviendas inadecuadas, que caracterizan a los grupos marginales, aumentan el riesgo de muerte de los menores de un año (Valenzuela de Mari, 1992).

Una vivienda, para alojar apropiadamente al hombre, debe reunir una serie de requisitos, que van desde el material predominante en los pisos, hasta las formas de abastecimiento de agua, las características del servicio sanitario y la disponibilidad de ciertos bienes material, todos ellos vinculados directamente con la higiene y, por consiguiente con la salud.

Para Abaleron y otros (1996), el problema básico observado en la vivienda responde por un lado, al agudo déficit de la infraestructura y de equipamiento comunitario y por el otro, en las características insalubres de la unidad de vivienda en sí misma. Todo ello lleva a la población a sumergirse en un ambiente proclive a producir variadas patologías físicas y psíquicas tanto a nivel individual como grupal.

Arriagada Luco (2003), señala que existen ciertos componentes específicos de la habitabilidad de la vivienda que incrementan la probabilidad de contraer algunas enfermedades, especialmente en los más pequeños. Si bien esa relación está mediatizada por un conjunto de determinantes próximos del nivel de salud (nivel de instrucción de la madre, residencia rural, uso de servicios cercanos, programas de salud locales), se identifican tres relaciones de causalidad que vinculan alojamiento y salud. Primero, la ausencia de servicios de agua potable se asocia a la mayor incidencia de diarreas, lo que puede incrementar a su vez los niveles de desnutrición; segundo, la ausencia de un sistema higiénico de eliminación de excretas (alcantarillados y fosas sépticas) favorecen a la incidencia de parásitos intestinales y enfermedades como la tifoidea y hepatitis $\mathrm{y}$, tercero, las viviendas de materialidad precaria $y / 0$ afectadas por el hacinamiento se relacionan con un mayor riesgo de enfermedades respiratorias.

Publicado en formato digital: Dras. Blanca Elizabeth Ponce, María Alejandra Fantín y Carola Leticia Bertone. ANÁLISIS ESPACIAL DE LOS DETERMINANTES SOCIOECONÓMICOS DE LA SALUD EN EL GRAN RESISTENCIA. Revista Geográfica Digital. IGUNNE. Facultad de Humanidades. UNNE. Año 11. № 22. Julio Diciembre. 2014. ISSN 1668-5180 Resistencia, Chaco.

En: http://hum.unne.edu.ar/revistas/geoweb/default.htm 
Por lo antes expuesto decidimos que la dimensión habitacional contemple las siguientes variables: Hogares con CALMAT ${ }^{18}$; Hogares con Viviendas Deficitarias ${ }^{19}$; Hogares con Hacinamiento por Cuarto $^{20}$; Hogares con Paredes de Adobe, Madera, Chapa y Cartón ${ }^{21}$ y Hogares con Piso de Tierra ${ }^{22}$.

\subsection{Dimensión Económica}

En esta dimensión hemos decido incorporar las siguientes variables: hogares con jefes y cónyuges desocupados ${ }^{23}$ y población mayor de 65 años de edad sin aportes jubilatorios. Ambas variables contribuyen de alguna manera a una dinámica demográfica caracterizada por la pobreza, ya que dichas variables no sólo atentan contra las posibilidades de subsistencia de la familia, sino que también la pone en una condición de privación, escasez y exclusión social.

De esta manera, nos referirnos a la desocupación de quienes representan el sostén económico de los hogares. Si bien, el desempleo puede afectar a ambos sexos, persiste el aumento de desempleo femenino en mayor cantidad que el masculino. Asimismo, la calidad del trabajo femenino sigue presentando notorias falencias, situación que afecta aún más a aquellos hogares que tienen a una mujer como jefa de hogar.

A la desocupación también se la asocia con la deserción escolar, la cual se concentra mayormente en sectores de bajos ingresos económicos donde los jóvenes se ven obligados a buscar formas de aumentar los ingresos familiares en empleos poco remunerados y una vez abandonados los estudios difícilmente son retomados.

Por su parte, la ausencia de una jubilación ${ }^{24}$, también se traduce en la carencia de una cobertura de una obra social o de algún plan privado de salud, lo cual impacta directamente sobre la salud de los adultos mayores, los cuales quedan expuestos a una mayor vulnerabilidad en relación a otros sectores de la población. A esto, debemos agregarle que, este sector poblacional debe enfrentar en soledad las situaciones de crisis de salud y todo tipo de urgencias domésticas, encontrándose desprotegidos para hacer frente a situaciones de enfermedades y accidentes.

\subsection{Dimensión Infraestructura}

En esta dimensión pretendemos analizar las condiciones ambientales de la población que reside en cada uno de los sectores del aglomerado, como así también los niveles de accesibilidad.

Las buenas condiciones de los caminos vecinales no sólo permiten el acceso de las personas a los puestos sanitarios, sino que favorecen el suministro de los insumos necesarios para la atención de la salud y la salida rápida de las ambulancias cuando éstas lo requieran.

Asimismo, la disponibilidad de un trasporte público que permita a las personas trasladarse desde su domicilio hasta el centro de salud más cercano, se vuelve indispensable en caso de urgencias, principalmente en determinados grupos sociales, como son: los ancianos, las mujeres con niños y las embarazadas.

Por este motivo, las variables seleccionadas para que conformen esta dimensión fueron: hogares sin servicio de transporte público a menos de 300 metros; Hogares sin alumbrado público y hogares sin al menos una cuadra de calle pavimentada.

A continuación, en la Tabla $\mathrm{N}^{\circ} 1$ tenemos a las 18 variables seleccionadas, destacando en cada una de ellas las Áreas Programáticas que presentan los mayores porcentajes.

Publicado en formato digital: Dras. Blanca Elizabeth Ponce, María Alejandra Fantín y Carola Leticia Bertone. ANÁLISIS ESPACIAL DE LOS DETERMINANTES SOCIOECONÓMICOS DE LA SALUD EN EL GRAN RESISTENCIA. Revista Geográfica Digital. IGUNNE. Facultad de Humanidades. UNNE. Año 11. № 22. Julio Diciembre. 2014. ISSN 1668-5180 Resistencia, Chaco.

En: http://hum.unne.edu.ar/revistas/geoweb/default.htm 
Revista Geográfica Digital. IGUNNE. Facultad de Humanidades. UNNE. Año 11. № 22. Julio - Diciembre 2014. ISSN 1668-5180 Resistencia, Chaco

\section{Tabla $\mathbf{N}^{\circ} 1$}

\begin{tabular}{|c|c|c|c|}
\hline DIMENSIÓN & INDICADOR & VARIABLE & $\begin{array}{l}\text { AREAS PROGRAMÁTICAS CON LOS } \\
\text { MAYORES PORCENTAJES }\end{array}$ \\
\hline \multirow{3}{*}{ Demográfica } & \multirow{3}{*}{ Estructura } & $\begin{array}{l}\text { 1. Niños Menores de } 5 \\
\text { años }\end{array}$ & $\begin{array}{l}\text { Barrio Cristo Rey }(21 \%) \text { - Barrio Toba } \\
(20 \%) \text { - Villa Don Andrés (19\%) - Rio Negro } \\
(18 \%) \text { - Pto. Vicentini }(17 \%)\end{array}$ \\
\hline & & $\begin{array}{l}\text { 2. Población Mayor de } 65 \\
\text { años }\end{array}$ & $\begin{array}{l}\text { Villa Alvear (11\%) - Villa Pegoraro (10\%) - } 4 \\
\text { de Junio (10\%) - Villa Odorico (10\%) - San } \\
\text { Fernando (10\%) }\end{array}$ \\
\hline & & 3. Índice de Masculinidad & $\begin{array}{l}\text { Barrio Cristo Rey (109) - Rio Negro (108) - } \\
\text { Villa Barberán (107) - Villa Prosperidad } \\
\text { (106) - Villa Elba (103) }\end{array}$ \\
\hline \multirow[b]{2}{*}{ Educación } & \multirow{2}{*}{$\begin{array}{l}\text { Nivel de } \\
\text { Instrucción }\end{array}$} & $\begin{array}{l}\text { 4. Población de } 18 \text { años y } \\
\text { más que no saben leer ni } \\
\text { escribir }\end{array}$ & $\begin{array}{l}\text { Barrio Toba }(14 \%) \text { - Pto. Vicentini }(14 \%) \text { - } \\
\text { Rio Negro }(12 \%) \text { - Barrio Cristo Rey }(12 \%) \text { - } \\
\text { Villa Prosperidad (10\%) }\end{array}$ \\
\hline & & $\begin{array}{l}\text { 5. Población de } 25 \text { años y } \\
\text { más con estudios terciarios } \\
\text { y universitarios completos }\end{array}$ & $\begin{array}{l}\text { Villa San Martin (21\%) - Villa Odorico (18\%) } \\
\text { - Villa Alvear (18\%) - Barrio España (14\%) - } \\
\text { Barrio Gral. Belgrano (14\%) }\end{array}$ \\
\hline \multirow{3}{*}{ Salud } & $\begin{array}{l}\text { Cobertura de } \\
\text { Salud }\end{array}$ & $\begin{array}{l}\text { 6. Población sin Obra } \\
\text { Social }\end{array}$ & $\begin{array}{l}\text { Barrio Cristo Rey }(84 \%) \text { - Barrio Toba } \\
(80 \%) \text { - Pto. Vicentini }(80 \%) \text { - Villa Don } \\
\text { Andrés (79\%) - Rio Negro (78\%) }\end{array}$ \\
\hline & \multirow{2}{*}{$\begin{array}{l}\text { Servicio } \\
\text { sanitario }\end{array}$} & $\begin{array}{l}\text { 7. Hogares sin Agua dentro } \\
\text { de la Vivienda y el Terreno }\end{array}$ & $\begin{array}{l}\text { Barrio Cristo Rey }(58 \%) \text { - Barrio Toba } \\
(50 \%) \text { - Pto. Vicentini }(49 \%) \text { - Villa Don } \\
\text { Andrés (48\%) - Rio Negro (48\%) }\end{array}$ \\
\hline & & $\begin{array}{l}\text { 8. Hogares con Inodoro sin } \\
\text { descarga de agua y } \\
\text { Hogares sin Inodoro }\end{array}$ & $\begin{array}{l}\text { Rio Negro }(61 \%) \text { - Villa Elba (58\%) - Pto. } \\
\text { Vicentini }(55 \%) \text { - Villa Forestación (54\%) - } \\
\text { Villa Don Andrés (54\%) }\end{array}$ \\
\hline \multirow{5}{*}{ Habitacional } & $\begin{array}{l}\text { Calidad } \\
\text { Material de la } \\
\text { Vivienda }\end{array}$ & 9. Hogares con CALMAT I & $\begin{array}{l}\text { B. Mujeres Argentinas ( } 82 \%) \text { - Barrio Santa } \\
\text { Inés }(64 \%) \text { - Barrio España }(61 \%) \text { - Santa } \\
\text { Rita II (59\%) - Villa San Martin (55\%) }\end{array}$ \\
\hline & $\begin{array}{l}\text { Tipo de } \\
\text { Vivienda }\end{array}$ & $\begin{array}{l}\text { 10. Hogares con Viviendas } \\
\text { Deficitarias }\end{array}$ & $\begin{array}{l}\text { Rio Negro }(64 \%) \text { - Villa Elba (64\%) - Villa } \\
\text { Prosperidad }(61 \%) \text { - Barrio Mapic }(60 \%) \text { - } \\
\text { Pto. Vicentini }(60 \%)\end{array}$ \\
\hline & Hacinamiento & $\begin{array}{l}\text { 11. Hogares con } \\
\text { Hacinamiento por Cuarto } \\
\text { (más de } 3 \text { personas) }\end{array}$ & $\begin{array}{l}\text { Barrio Toba }(20 \%) \text { - Rio Negro }(20 \%) \text { - Villa } \\
\text { Don Andrés }(17 \%) \text { - Villa Urquiza (17\%) - } \\
\text { Villa Elba }(15 \%)\end{array}$ \\
\hline & $\begin{array}{l}\text { Características } \\
\text { de las Paredes }\end{array}$ & $\begin{array}{l}\text { 12. Hogares con Paredes } \\
\text { de Adobe, Madera, Chapa } \\
\text { y Cartón }\end{array}$ & $\begin{array}{l}\text { Rio Negro (29\%) - Barrio Toba (27\%) - Villa } \\
\text { Don Alberto (19\%) - Barrio Cristo Rey } \\
\text { (13\%) - Villa Don Andrés (13\%) }\end{array}$ \\
\hline & $\begin{array}{l}\text { Características } \\
\text { del Piso }\end{array}$ & $\begin{array}{l}\text { 13. Hogares con Piso de } \\
\text { Tierra }\end{array}$ & $\begin{array}{l}\text { Rio Negro }(34 \%) \text { - Villa Don Alberto }(20 \%) \text { - } \\
\text { Barrio Toba }(19 \%) \text { - Villa Elba }(16 \%) \text { - Villa } \\
\text { Prosperidad }(15 \%)\end{array}$ \\
\hline \multirow{2}{*}{ Económica } & $\begin{array}{l}\text { Condición de } \\
\text { Actividad }\end{array}$ & $\begin{array}{l}\text { 14. Hogares con Jefes y } \\
\text { Cónyuge Desocupados }\end{array}$ & $\begin{array}{l}\text { Cacique Pelayo (7\%) - Barrio La Toma (6\%) } \\
\text { - Villa Elba }(6 \%) \text { - Barrio Mapic (6\%) - Villa } \\
\text { Don Andrés }(6 \%)\end{array}$ \\
\hline & $\begin{array}{l}\text { Aportes } \\
\text { jubilatorios }\end{array}$ & $\begin{array}{l}\text { 15. Población mayor de } 65 \\
\text { años sin jubilación. }\end{array}$ & $\begin{array}{l}\text { Villa Prosperidad (67\%) - Villa Urquiza } \\
(62 \%) \text { - Barrio Cristo Rey }(60 \%) \text { - Villa Don } \\
\text { Alberto }(60 \%) \text { - Villa Elba }(58 \%)\end{array}$ \\
\hline \multirow{3}{*}{ Infraestructura } & $\begin{array}{l}\text { Servicios } \\
\text { públicos }\end{array}$ & $\begin{array}{l}\text { 16. Hogares sin transporte } \\
\text { público }\end{array}$ & $\begin{array}{l}\text { Villa Prosperidad ( } 78 \%) \text { - Villa Don Andrés } \\
(66 \%) \text { - Villa Don Alberto (57\%) - Villa } \\
\text { Hortensia }(56 \%) \text { - Villa Ghio (38\%) }\end{array}$ \\
\hline & & $\begin{array}{l}\text { 17. Hogares sin alumbrado } \\
\text { publico }\end{array}$ & $\begin{array}{l}\text { Villa Prosperidad (33\%) - Villa Don Andrés } \\
(32 \%) \text { - Villa Don Alberto (31\%) - Villa } \\
\text { Hortensia (27\%) - Villa Ghio (19\%) }\end{array}$ \\
\hline & & $\begin{array}{l}\text { 18. Hogares } \sin \\
\text { pavimentadas }\end{array}$ & $\begin{array}{l}\text { Barrio Mapic (100\%) - Villa Prosperidad } \\
(100 \%) \text { - Villa Urquiza (96\%) - Dr.L. } \\
\text { Maradona (96\%) - Barrio Cristo Rey (95\%) }\end{array}$ \\
\hline
\end{tabular}

Fuente: Elaboración Propia, en base a los datos del INDEC (2001).

Publicado en formato digital: Dras. Blanca Elizabeth Ponce, María Alejandra Fantín y Carola Leticia Bertone. ANÁLISIS ESPACIAL DE LOS DETERMINANTES SOCIOECONÓMICOS DE LA SALUD EN EL GRAN RESISTENCIA. Revista Geográfica Digital. IGUNNE. Facultad de Humanidades. UNNE. Año 11. № 22. Julio Diciembre. 2014. ISSN 1668-5180 Resistencia, Chaco.

En: http://hum.unne.edu.ar/revistas/geoweb/default.htm 
Revista Geográfica Digital. IGUNNE. Facultad de Humanidades. UNNE. Año 11. № 22. Julio - Diciembre 2014. ISSN 1668-5180 Resistencia, Chaco

\section{El Análisis de Conglomerados}

Reciben esta denominación una gran variedad de métodos que pueden usarse para encontrar qué entidades (sean éstas sujetos u objetos) de un conjunto determinado, son similares entre sí. Estos métodos proporcionan clasificaciones a partir de datos inicialmente no clasificados, tratando de encontrar grupos en los datos (Picón Prado y otros, 2007).

Son apropiados a la hora de extraer información de un conjunto de datos sin imponer restricciones previas en forma de modelos estadísticos, al menos de forma explícita y por ello, puede llegar a ser muy útil como una herramienta de elaboración de hipótesis acerca del problema considerado sin imponer patrones o teorías previamente establecidas ${ }^{25}$.

Existen dos grandes grupos de técnicas de análisis conglomerados: los métodos jerárquicos y no jerárquicos.

a) Métodos jerárquicos: son aquellos que para formar un conglomerado nuevo une o separa alguno ya existente para dar origen a otros dos de forma que se maximice una similaridad o se minimice una distancia ${ }^{26}$. Inicialmente cada caso es un grupo en sí mismo y sucesivamente se van fusionando grupos cercanos hasta que todos los individuos confluyen en un solo grupo.

b) Métodos no jerárquicos: se clasifican los individuos en $k$ grupos, estudiando todas las particiones de individuos en esos $k$ grupos y eligiendo la mejor partición. Las ventajas que presentan estos métodos son las siguientes:

$\checkmark$ Se conoce a priori el número de $\mathrm{k}$ grupos.

$\checkmark$ Cada observación es asignada a un grupo.

$\checkmark$ Maximiza la homogeneidad dentro de los grupos.

$\checkmark$ Maximiza la heterogeneidad entre grupos.

El análisis no jerárquico, a diferencia del análisis jerárquico, parte de la matriz original de las puntuaciones y no de la matriz de proximidades, y los conglomerados resultantes no están anidados unos en otros, sino que son independientes. Muchos autores consideran que los métodos no jerárquicos son los que mejor se adaptan a los estudios sociológicos y de mercados, caracterizados por el empleo de grandes conjuntos de datos. Por esta razón, se aconseja su utilización cuando se desea, no tanto analizar la estructura jerárquica de los individuos, sino conocer el número de grupos construidos y las características de cada uno.

Entre los métodos no jerárquicos, el más común es el de K-medias sin especificar los centros de los conglomerados. Con centros desconocidos, el método K-medias comienza con una división del conjunto de los datos en ( $\mathrm{x}$ ) grupos configurados al azar y posteriormente busca mejorar esta primera clasificación reasignando los elementos al centroide del conglomerado más cercano, tratando de reducir la distancia media entre cada elemento de un grupo y su centroide.

De la Fuente Fernández (2011), explica el proceso de funcionamiento de este método de la siguiente manera:

$1^{\circ}$ Se comienza con una partición inicial de los datos en un específico número de agrupamientos, para calcular posteriormente el centroide de cada uno. Esta partición inicial comienza con los casos más alejados entre sí.

$2^{\circ}$ El siguiente paso trata de reasignar cada caso al agrupamiento más cercano, aquel cuya distancia al centro de gravedad del conglomerado sea menor. No hay que olvidar que en el método de K-medias, al formar parte de los métodos de reasignación, un caso asignado a un conglomerado en una determinada iteración puede ser reasignado a otro caso en una iteración posterior.

Publicado en formato digital: Dras. Blanca Elizabeth Ponce, María Alejandra Fantín y Carola Leticia Bertone. ANÁLISIS ESPACIAL DE LOS DETERMINANTES SOCIOECONÓMICOS DE LA SALUD EN EL GRAN RESISTENCIA. Revista Geográfica Digital. IGUNNE. Facultad de Humanidades. UNNE. Año 11. № 22. Julio Diciembre. 2014. ISSN 1668-5180 Resistencia, Chaco.

En: http://hum.unne.edu.ar/revistas/geoweb/default.htm 
$3^{\circ}$ Calcula los nuevos centroides de los conglomerados cada vez que se incorpora un nuevo caso.

$4^{\circ}$ Repite alternativamente el segundo y el tercer paso hasta que ninguna reasignación de un caso a un nuevo conglomerado permita reducir más la distancia entre los individuos dentro de cada agrupamiento, ni aumentar la distancia entre los distintos conglomerados.

En esta oportunidad, se decidió trabajar con el método de las K-medias ${ }^{27}$ de clasificación no jerárquica, por ser el más importante desde el punto de vista conceptual y práctico. Es muy útil cuando queremos clasificar un gran número de casos y/o para refinar una clasificación obtenida utilizando un método jerárquico ${ }^{28}$.

Por otra parte, debido a la heterogeneidad del espacio estudiado, debimos tomar ciertas decisiones con respecto a la cantidad de agrupaciones a obtener. Estas decisiones surgieron a partir de identificar cierta analogía entre la expansión urbana del Gran Resistencia y el modelo espacial de crecimiento urbano propuesto por Burgess (1929).

En el año 1920, el sociólogo Ernest Watson Burgess elaboró la Teoría Concéntrica, donde defendía la división del suelo urbano en anillos concéntricos en torno al área central. El autor afirmaba que el precio del suelo descendía en la medida que nos alejábamos del área central. Asimismo, la ciudad tiene un crecimiento hacia afuera y como consecuencia de ello, las clases sociales más acomodadas ocupan los espacios más dignos, mientras que la población menos afortunada tiende a desplazarse hacia la periferia (Burgess, 1929).

Varios autores del ámbito local como por ejemplo, Bruniard y Bolsi (1975); Fantín (1999); Foschiatti de Dell 'Orto (1991); Manoiloff (1992) y Meichtry y Mignone (2001), han coincidido de alguna manera, en la existencia de anillos concéntricos en la configuración espacial del Gran Resistencia, como así también la localización periférica de la población menos favorecida. Sin embargo, ninguno de ellos ha expresado la cantidad exacta de anillos que pueden distinguirse. Por este motivo y, basándonos en las normas cartográficas ${ }^{29}$, hemos decido obtener cinco conglomerados. Los autores mencionados antes, nos han aproximado a la idea de que podrían diferenciarse tres anillos principales; no obstante, con el objeto de poder incluir algunos casos aislados en nuestro estudio, que podrían marcar alguna diferencia en la configuración espacial, hemos decidido sumarle dos conglomerados más.

\subsection{Aplicación del Método de las K-medias de Clasificación no Jerárquica}

Debido a que, las variables seleccionadas en este trabajo, poseen características diferentes y, el peso que tienen sobre los radios no es homogéneo, ya que no todos tienen la misma superficie geográfica, número de población y número de hogares, se decidió primeramente tipificarlas ${ }^{30}$, tarea que se realizó automáticamente a través del programa SPSS. Dicho programa nos ofrece diferentes salidas en formato de tablas, las cuales se presentan a continuación.

En la Tabla $N^{\circ} 2$ encontramos los Centro de Conglomerados Iniciales, mostrándose los valores medios de las variables de cada conglomerado (centroide). Por defecto, el programa elige casos que son distintos y usa los valores de éstos para definir los conglomerados iniciales.

Tabla $\mathbf{N}^{\circ}$ 2. Centros Iniciales de los Conglomerados

\begin{tabular}{|l|c|c|c|c|c|}
\hline & \multicolumn{5}{|c|}{ Conglomerado } \\
\cline { 2 - 6 } & $\mathbf{1}$ & $\mathbf{2}$ & $\mathbf{3}$ & $\mathbf{4}$ & $\mathbf{5}$ \\
\hline Niños menores de 5 años & 1,478 & $-0,245$ & 1,297 & $-1,619$ & 3,266 \\
\hline P. mayor de 65 años & $-1,057$ & $-1,205$ & $-0,142$ & 3,996 & $-1,224$ \\
\hline İndice de Masculinidad & 0,229 & 11,818 & 1,941 & $-1,486$ & $-0,098$ \\
\hline P.de 18 años y más que no saben leer ni escribir & 1,626 & 1,087 & 6,578 & $-0,579$ & $-0,338$ \\
\hline
\end{tabular}

Publicado en formato digital: Dras. Blanca Elizabeth Ponce, María Alejandra Fantín y Carola Leticia Bertone. ANÁLISIS ESPACIAL DE LOS DETERMINANTES SOCIOECONÓMICOS DE LA SALUD EN EL GRAN RESISTENCIA. Revista Geográfica Digital. IGUNNE. Facultad de Humanidades. UNNE. Año 11. № 22. Julio Diciembre. 2014. ISSN 1668-5180 Resistencia, Chaco.

En: http://hum.unne.edu.ar/revistas/geoweb/default.htm 
Revista Geográfica Digital. IGUNNE. Facultad de Humanidades. UNNE. Año 11. № 22. Julio - Diciembre 2014. ISSN 1668-5180 Resistencia, Chaco

\begin{tabular}{|l|c|c|c|c|c|}
\begin{tabular}{|l|c|c|c|} 
P.de 25 años y más con estudios terciarios y \\
universitarios completos
\end{tabular} & $-0,859$ & $-0,686$ & 0,262 & 1,811 & $-0,959$ \\
\hline P. sin Obra Social & 1,409 & 1,711 & 1,903 & $-1,735$ & 1,834 \\
\hline H. sin Agua dentro de la Vivienda y el Terreno & 1,792 & 2,551 & 1,688 & $-0,880$ & $-0,620$ \\
\hline H. con Inodoro sin descarga de agua y H. sin Inodoro & 1,798 & 1,953 & 1,218 & $-0,972$ & $-0,814$ \\
\hline H. con CALMAT I & $-1,550$ & $-1,262$ & $-1,554$ & 1,193 & $-1,734$ \\
\hline H. con Viviendas Deficitarias & 1,755 & 1,789 & 2,365 & $-0,985$ & $-0,817$ \\
\hline H. con Hacinamiento por Cuarto (más de 3 personas) & 2,349 & 2,571 & 1,824 & $-0,899$ & 0,553 \\
\hline H. con Paredes de Adobe, Madera, Chapa y Cartón & 1,760 & 3,997 & 2,058 & $-0,558$ & $-0,325$ \\
\hline H. con Piso de Tierra & 1,944 & 3,554 & 3,505 & $-0,563$ & $-0,363$ \\
\hline H. con Jefes y Cónyuge Desocupados & 6,060 & $-0,090$ & 2,202 & $-0,834$ & 0,331 \\
\hline P. mayor de 65 años sin jubilación & 0,786 & 2,210 & 2,632 & $-1,762$ & 1,893 \\
\hline H. sin transporte público & $-0,492$ & 2,828 & 3,868 & $-0,492$ & 2,378 \\
\hline H. sin alumbrado publico & $-0,433$ & 3,074 & 6,976 & $-0,433$ & 0,255 \\
\hline H. sin calles pavimentadas & 0,633 & $-0,039$ & $-0,736$ & $-1,128$ & $-0,265$ \\
\hline
\end{tabular}

Fuente: Elaboración propia, en base a los Datos del INDEC (2001).

Una vez que se tienen los valores medios de las variables de cada conglomerado (centroide), se calcula la distancia de cada individuo a cada conglomerado y se le asigna aquel cuya distancia euclídea al centroide del conglomerado sea menor. De esta manera, si por término medio esta distancia es grande o pequeña, indica una mayor o menor cohesión del grupo. Finalmente, se recalculan los centroide de los nuevos conglomerados.

La Tabla $N^{\circ} 3$ representa el Historial de Interacciones y muestra el progreso del proceso de conglomeración en cada etapa. En esta ocasión, se estableció que fueran diez las interacciones para lograr la convergencia. Podemos observar entonces que, el segundo conglomerado no sufre ninguna modificación; mientras que el tercero, en la séptima iteración, el proceso de redistribución de las unidades se paraliza porque los centro de conglomerados no experimentan cambios.

Tabla $\mathbf{N}^{\circ}$ 3. Historial de Iteraciones

\begin{tabular}{|l|r|r|r|r|r|}
\hline \multirow{2}{*}{ Iteración } & \multicolumn{6}{|c|}{ Cambio en los centros de los conglomerados } \\
\cline { 2 - 6 } & \multicolumn{1}{|c|}{$\mathbf{1}$} & \multicolumn{1}{|c|}{$\mathbf{2}$} & \multicolumn{1}{l|}{$\mathbf{3}$} & \multicolumn{1}{l|}{$\mathbf{4}$} & \multicolumn{1}{c|}{$\mathbf{5}$} \\
\hline 1 & 4,939 &, 000 & 5,765 & 4,044 & 4,816 \\
\hline 2 &, 876 &, 000 & 1,228 &, 128 &, 432 \\
\hline 3 &, 693 &, 000 &, 892 &, 029 &, 221 \\
\hline 4 &, 433 &, 000 &, 481 &, 088 &, 201 \\
\hline 5 &, 336 &, 000 &, 154 &, 073 &, 232 \\
\hline 6 &, 202 &, 000 &, 171 &, 083 &, 188 \\
\hline 7 &, 111 &, 000 &, 000 &, 147 &, 183 \\
\hline 8 &, 043 &, 000 &, 000 &, 070 &, 084 \\
\hline 9 &, 071 &, 000 &, 000 &, 014 &, 045 \\
\hline 10 &, 000 &, 000 &, 000 &, 039 &, 039 \\
\hline
\end{tabular}

Fuente: Elaboración propia, en base a los Datos del INDEC (2001).

Por su parte, en la Tabla № 4 podemos ver los Centros de los Conglomerados Finales. Los valores son las medias de cada variable en cada conglomerado final. Los mismos, reflejan los atributos del caso prototipo para cada conglomerado y, si comparamos estos resultados con los de la Tabla $\mathrm{N}^{\circ} 2$ observaremos que el centro conglomerado del segundo no cambia.

Publicado en formato digital: Dras. Blanca Elizabeth Ponce, María Alejandra Fantín y Carola Leticia Bertone. ANÁLISIS ESPACIAL DE LOS DETERMINANTES SOCIOECONÓMICOS DE LA SALUD EN EL GRAN RESISTENCIA. Revista Geográfica Digital. IGUNNE. Facultad de Humanidades. UNNE. Año 11. № 22. Julio Diciembre. 2014. ISSN 1668-5180 Resistencia, Chaco.

En: http://hum.unne.edu.ar/revistas/geoweb/default.htm 
Revista Geográfica Digital. IGUNNE. Facultad de Humanidades. UNNE. Año 11. № 22. Julio - Diciembre 2014. ISSN 1668-5180 Resistencia, Chaco

Tabla $\mathbf{N}^{\circ} 4$

Centros de los conglomerados finales

\begin{tabular}{|l|r|r|r|r|r|}
\hline & \multicolumn{5}{|c|}{ Conglomerado } \\
\cline { 2 - 6 } & \multicolumn{1}{|c|}{1} & \multicolumn{1}{|c|}{2} & \multicolumn{1}{c|}{3} & \multicolumn{1}{c|}{4} & \multicolumn{1}{c|}{5} \\
\hline Niños menores de 5 años & 1,013 & $-0,245$ & 1,814 & $-0,899$ & 0,108 \\
\hline P. mayor de 65 años & $-0,791$ & $-1,205$ & $-0,828$ & 0,830 & $-0,282$ \\
\hline Índice de Masculinidad & 0,410 & 11,818 & 0,837 & $-0,540$ & 0,049 \\
\hline P.de 18 años y más que no saben leer ni escribir & 1,025 & 1,087 & 2,059 & $-0,729$ & $-0,132$ \\
\hline $\begin{array}{l}\text { P.de 25 años y más con estudios terciarios y } \\
\text { universitarios completos }\end{array}$ & $-0,791$ & $-0,686$ & $-0,770$ & 0,915 & $-0,403$ \\
\hline P. sin Obra Social & & & & & \\
\hline H. sin Agua dentro de la Vivienda y el Terreno & 1,149 & 1,711 & 1,632 & $-0,970$ & 0,134 \\
\hline $\begin{array}{l}\text { H. con Inodoro sin descarga de agua y H. sin } \\
\text { Inodoro }\end{array}$ & 1,100 & 2,551 & 2,187 & $-0,807$ & $-0,119$ \\
\hline H. con CALMAT I & $-1,212$ & $-1,262$ & $-1,405$ & 0,926 & $-0,100$ \\
\hline H. con Viviendas Deficitarias & 1,155 & 1,789 & 1,909 & $-0,858$ & $-0,040$ \\
\hline $\begin{array}{l}\text { H. con Hacinamiento por Cuarto (más de 3 } \\
\text { personas) }\end{array}$ & 1,152 & 2,571 & 2,109 & $-0,790$ & $-0,148$ \\
\hline $\begin{array}{l}\text { H. con Paredes de Adobe, Madera, Chapa y } \\
\text { Cartón }\end{array}$ & 0,442 & 3,997 & 2,848 & $-0,508$ & $-0,226$ \\
\hline H. con Piso de Tierra & & & & & \\
\hline H. con Jefes y Cónyuge Desocupados & 0,580 & 3,554 & 2,897 & $-0,545$ & $-0,262$ \\
\hline P. mayor de 65 años sin jubilación & 0,915 & $-0,090$ & 0,545 & $-0,691$ & 0,161 \\
\hline H. sin transporte público & 1,038 & 2,210 & 1,635 & $-0,803$ & $-0,001$ \\
\hline H. sin alumbrado publico & 0,725 & 2,828 & 1,704 & $-0,443$ & $-0,223$ \\
\hline H. sin calles pavimentadas & 0,248 & 3,074 & 2,436 & $-0,369$ & $-0,194$ \\
\hline
\end{tabular}

Fuente: Elaboración propia, en base a los Datos del INDEC (2001).

Conocidos los centros de los conglomerados, es interesante conocer el grado de diferencia entre ellos, considerando la distancia entre los centroides ${ }^{31}$. Las mayores distancias nos indican una mayor diferencia y las menores distancia por lo tanto, mayor similitud. De esta manera, podemos ver en la Tabla $\mathrm{N}^{\circ} 5$ que:

$\checkmark$ El conglomerado 1 es igualmente similar al conglomerado 2 .

$\checkmark$ El conglomerado 2 es igualmente similar al conglomerado 1,5 y 3 .

$\checkmark$ El conglomerado 3 es igualmente similar al conglomerado 1.

$\checkmark$ El conglomerado 4 es igualmente similar al conglomerado 1 .

$\checkmark$ El conglomerado 5 es igualmente similar al conglomerado 1 y 4 .

Tabla $\mathbf{N}^{\circ} 5$

\begin{tabular}{|l|c|c|c|c|c|}
\hline \multicolumn{6}{|c|}{ Distancias entre los centros de los conglomerados finales } \\
\hline Conglomerado & 1 & 2 & 3 & 4 & 5 \\
\hline
\end{tabular}

Publicado en formato digital: Dras. Blanca Elizabeth Ponce, María Alejandra Fantín y Carola Leticia Bertone. ANÁLISIS ESPACIAL DE LOS DETERMINANTES SOCIOECONÓMICOS DE LA SALUD EN EL GRAN RESISTENCIA. Revista Geográfica Digital. IGUNNE. Facultad de Humanidades. UNNE. Año 11. № 22. Julio Diciembre. 2014. ISSN 1668-5180 Resistencia, Chaco.

En: http://hum.unne.edu.ar/revistas/geoweb/default.htm 
Revista Geográfica Digital. IGUNNE. Facultad de Humanidades. UNNE. Año 11. № 22. Julio - Diciembre 2014. ISSN 1668-5180 Resistencia, Chaco

\begin{tabular}{|r|r|r|r|r|r|}
$\mathbf{1}$ & & 13,218 & 4,813 & 7,127 & 3,907 \\
\hline $\mathbf{2}$ & 13,218 & & 11,435 & 16,803 & 14,976 \\
\hline $\mathbf{3}$ & 4,813 & 11,435 & & 10,616 & 7,997 \\
\hline $\mathbf{4}$ & 7,127 & 16,803 & 10,616 & & 3,490 \\
\hline $\mathbf{5}$ & 3,907 & 14,976 & 7,997 & 3,490 & \\
\hline
\end{tabular}

Fuente: Elaboración propia, en base a los Datos del INDEC (2001).

\subsection{Validación del Análisis de Conglomerados}

Para justificar las agrupaciones podemos hacerlo mediante la demostración de que existen diferencias significativas entre cada una de ellas.

Estas diferencias resultan ser obvias desde cierto punto de vista, y son utilizadas solo para propósitos meramente descriptivos, ya que uno de los objetivos del análisis de conglomerados es precisamente maximizar las diferencias entre los grupos de casos.

En la Tabla $N^{\circ} 6$ se exponen los resultados de aplicar un ANOVA para cada una de las variables analizadas. En una primera instancia, se observa que existen diferencias significativas en todas las variables al 1 y al $5 \%$.

La media cuadrática (variabilidad) entre grupos aparece en la segunda columna y la media cuadrática dentro de cada grupo en la cuarta columna. El ratio entre ambas medias se presenta en la sexta columna, de forma que los altos valores del estadístico $F$ indican que la variabilidad entre los grupos es mayor que la variabilidad dentro de cada grupo $(65,253 / 0,284=229,743)$, probando que los conglomerados elaborados son homogéneos ${ }^{32}$.

Tabla $\mathbf{N}^{\circ} 6$

\begin{tabular}{|c|c|c|c|c|c|c|}
\hline \multicolumn{7}{|c|}{ ANOVA } \\
\hline & \multicolumn{2}{|c|}{ Conglomerado } & \multicolumn{2}{|c|}{ Error } & \multirow[b]{2}{*}{$\mathbf{F}$} & \multirow[b]{2}{*}{ Sig. } \\
\hline & \begin{tabular}{c|} 
Media \\
cuadrática
\end{tabular} & gl & $\begin{array}{c}\text { Media } \\
\text { cuadrática }\end{array}$ & gl & & \\
\hline Niños menores de 5 años & 65,253 & 4 & 0,284 & 363 & 229,743 & 0,000 \\
\hline P. mayor de 65 años & 41,456 & 4 & 0,551 & 363 & 75,299 & 0,000 \\
\hline Índice de Masculinidad & 52,048 & 4 & 0,246 & 363 & 211,812 & 0,000 \\
\hline $\begin{array}{l}\text { P.de } 18 \text { años y más que no saben } \\
\text { leer ni escribir }\end{array}$ & 62,263 & 4 & 0,327 & 363 & 190,224 & 0,000 \\
\hline $\begin{array}{l}\text { P.de } 25 \text { años y más con estudios } \\
\text { terciarios y universitarios completos }\end{array}$ & 48,656 & 4 & 0,472 & 363 & 103,027 & 0,000 \\
\hline P. sin Obra Social & 71,873 & 4 & 0,203 & 363 & 353,614 & 0,000 \\
\hline $\begin{array}{l}\text { H. sin Agua dentro de la Vivienda y } \\
\text { el Terreno }\end{array}$ & 73,551 & 4 & 0,201 & 363 & 366,179 & 0,000 \\
\hline $\begin{array}{l}\text { H. con Inodoro sin descarga de } \\
\text { agua y H. sin Inodoro }\end{array}$ & 70,332 & 4 & 0,236 & 363 & 297,932 & 0,000 \\
\hline H. con CALMAT I & 66,773 & 4 & 0,266 & 363 & 250,798 & 0,000 \\
\hline H. con Viviendas Deficitarias & 70,446 & 4 & 0,234 & 363 & 300,922 & 0,000 \\
\hline $\begin{array}{l}\text { H. con Hacinamiento por Cuarto } \\
\text { (más de } 3 \text { personas) }\end{array}$ & 72,822 & 4 & 0,209 & 363 & 348,709 & 0,000 \\
\hline $\begin{array}{l}\text { H. con Paredes de Adobe, Madera, } \\
\text { Chapa y Cartón }\end{array}$ & 66,575 & 4 & 0,279 & 363 & 238,482 & 0,000 \\
\hline H. con Piso de Tierra & 71,789 & 4 & 0,222 & 363 & 323,798 & 0,000 \\
\hline
\end{tabular}

Publicado en formato digital: Dras. Blanca Elizabeth Ponce, María Alejandra Fantín y Carola Leticia Bertone. ANÁLISIS ESPACIAL DE LOS DETERMINANTES SOCIOECONÓMICOS DE LA SALUD EN EL GRAN RESISTENCIA. Revista Geográfica Digital. IGUNNE. Facultad de Humanidades. UNNE. Año 11. № 22. Julio Diciembre. 2014. ISSN 1668-5180 Resistencia, Chaco.

En: http://hum.unne.edu.ar/revistas/geoweb/default.htm 
Revista Geográfica Digital. IGUNNE. Facultad de Humanidades. UNNE. Año 11. № 22. Julio - Diciembre 2014. ISSN 1668-5180 Resistencia, Chaco

\begin{tabular}{|l|r|r|r|r|r|r|}
$\begin{array}{l}\text { H. con Jefes y Cónyuge } \\
\text { Desocupados }\end{array}$ & 33,174 & 4 & 0,645 & 363 & 51,448 & 0,000 \\
\hline P. mayor de 65 años sin jubilación & 57,546 & 4 & 0,377 & 363 & 152,683 & 0,000 \\
\hline H. sin transporte público & 36,716 & 4 & 0,609 & 363 & 60,337 & 0,000 \\
\hline H. sin alumbrado publico & 45,008 & 4 & 0,517 & 363 & 87,006 & 0,000 \\
\hline H. sin calles pavimentadas & 46,605 & 4 & 0,497 & 363 & 93,827 & 0,000 \\
\hline
\end{tabular}

Las pruebas $\mathrm{F}$ sólo se deben utilizar con una finalidad descriptiva puesto que los conglomerados han sido elegidos para maximizar las diferencias entre los casos en diferentes conglomerados. Los niveles críticos no son corregidos, por lo que no pueden interpretarse como pruebas de la hipótesis de que los centros de los conglomerados son iguales.

Fuente: Elaboración propia, en base a los Datos del INDEC (2001).

Asimismo, si analizamos los valores $F$, podemos reconocer cuáles son las variables que tienen mayor y menor participación en el proceso de agrupamiento (Tabla $N^{\circ} 7$ ).

Tabla $\mathbf{N}^{\circ} 7$

\begin{tabular}{|c|l|l|}
\hline Orden & $\begin{array}{l}\text { Mayor participación en la formación } \\
\text { de los conglomerados }\end{array}$ & $\begin{array}{c}\text { Menor participación en la formación } \\
\text { de los conglomerados }\end{array}$ \\
\hline $1^{\circ}$ & $\begin{array}{l}\text { Hogares sin Agua dentro de la Vivienda } \\
\text { y el Terreno. }\end{array}$ & Hogares con Jefes y Cónyuges. \\
\hline $2^{\circ}$ & Población sin Obra Social. & Hogares sin Transporte Público. \\
\hline $3^{\circ}$ & $\begin{array}{l}\text { Hogares con Hacinamiento por Cuarto } \\
\text { (más de 3 personas). }\end{array}$ & Población mayor de 65 años. \\
\hline $4^{\circ}$ & Hogares con Piso de Tierra. & Hogares sin alumbrado público. \\
\hline $5^{\circ}$ & Hogares con Viviendas Deficitarias. & Hogares sin calles pavimentadas. \\
\hline
\end{tabular}

Fuente: Elaboración propia, en base a los Datos del INDEC (2001).

\section{Análisis de los Escenarios posibles de los Determinantes Socioeconómicos de la Salud}

A continuación presentamos una caracterización de los cinco escenarios posibles de los determinantes socioeconómicos de la salud en el Gran Resistencia ${ }^{33}$. La distribución espacial de los mismos, se muestran a su vez, en el Mapa $\mathrm{N}^{\circ} 3$.

Debemos aclarar que, la metodología aquí empleada, no nos permite trabajar a nivel de Áreas Programáticas, ya que requiere un mayor número de casos (radios censales). Por esta razón el mapa debió realizarse inicialmente a nivel de radios censales y posteriormente, mediante la superposición de mapas, pudimos caracterizar también a las Áreas Programáticas y los CRR. Asimismo, incluimos en el mapa la localización de los barrios, con el objeto de contar con un mayor grado de desagregación de la información.

* Situación Crítica muy Alta (Conglomerado 2): si bien, se encuentra constituido por un solo radios censales, nuestra idea fue analizar también algunos casos aislados que aporten a la configuración espacial del aglomerado. Por este motivo, hemos decidido no suprimir esta observación, tal como lo sugieren algunos autores en estos casos. En este conglomerado, gran parte de las variables seleccionadas poseen valores altos, entre las cuales podemos mencionar: índice de Masculinidad; hogares con paredes de adobe, madera, chapa y cartón; hogares con piso de tierra; hogares sin alumbrado y transporte público; hacinamiento por cuarto: hogares sin agua dentro de la vivienda y el terreno; población mayor de 65 años sin jubilación; hogares con inodoro sin descarga de agua y hogares sin inodoro; viviendas deficitarias; población sin obra social y población de 18 años y más que no saben leer ni escribir.

Publicado en formato digital: Dras. Blanca Elizabeth Ponce, María Alejandra Fantín y Carola Leticia Bertone. ANÁLISIS ESPACIAL DE LOS DETERMINANTES SOCIOECONÓMICOS DE LA SALUD EN EL GRAN RESISTENCIA. Revista Geográfica Digital. IGUNNE. Facultad de Humanidades. UNNE. Año 11. № 22. Julio Diciembre. 2014. ISSN 1668-5180 Resistencia, Chaco.

En: http://hum.unne.edu.ar/revistas/geoweb/default.htm 
* Situación Crítica Alta (Conglomerado 3): lo integran 24 radios censales situados en la periferia del Gran Resistencia. Tiene valores altos en: hogares con piso de tierra; hogares con paredes de adobe, madera, chapa y cartón; hogares sin alumbrado público y transporte público; hogares sin agua dentro de la vivienda y el terreno; hacinamiento por cuarto; población de 18 años y más que no saben leer ni escribir; hogares con inodoro sin descarga de agua y hogares sin inodoro; viviendas deficitarias; niños menores de 5 años; población mayor de 65 años sin jubilación y población sin obra social.

- Situación Crítica Intermedia (Conglomerado 1): conformado por 67 radios censales. Se caracteriza por tener principalmente viviendas deficitarias; hacinamiento por cuarto; población sin obra social y hogares con inodoro sin descarga de agua y sin inodoro. Al mismo tiempo, tiene valores altos en: población mayor de 65 años sin jubilación; población de 18 años y más que no saben leer ni escribir y niños menores de 5 años.

- Situación Crítica Baja (Conglomerado 5): integrado por 138 radios censales. Se localizan de manera circundante al conglomerado 4. Debemos aclarar que, al igual que en conglomerado anterior, los valores no se presentan muy elevados, sin embargo son útiles para la caracterización del espacio estudiado. En este sentido, se destacan las variables: hogares sin calles pavimentadas; hogares con jefes y cónyuge desocupados; población sin obra social; niños menores de 5 año e índice de masculinidad.

* Mejores Situaciones (Conglomerado 4): forman parte de este escenario 138 radios censales ubicados en el centro de las localidades que integran el Gran Resistencia. Si bien los valores no son tan elevados como en los conglomerados anteriores, los tomamos como aceptables para nuestro análisis. De esta manera, se caracteriza por tener: CALMAT I; población de 25 años y más con estudios terciarios y universitarios completos y población Mayor de 65 años. Los mejores indicadores habitacionales y educacionales, determinan que la población que vive en áreas, tengan mejores herramientas para hacer frente a los riesgos de salud, vinculados con el contexto donde viven.

De esta manera, debido a la presencia de ciertas variables que las podríamos llamar positivas para la salud de las personas, encontramos situaciones más favorables en el centro del aglomerado y, principalmente próximas a las avenidas principales que lo configuran (Sarmiento, Alverdi, 9 de julio y 25 de Mayo). Para dar algunos ejemplos, podemos mencionar en el CRR "Villa Libertad" a las Áreas Programáticas España, Alvear, Pegoraro, General Belgrano y General Obligado; en el CRR "Villa Río Negro a Odorico, San Martín, Los Lirios y Mujeres Argentinas; y en el CRR "Pedro Biolchi" a 4 de Junio y Forestación.

En la medida que nos alejamos de las avenidas principales, los determinantes socioeconómicos de la salud se van tornando más desfavorables. Así, podemos nombrar en el CRR "Villa Libertad" a las Áreas Programáticas Don Alberto y Don Andrés; en el CRR "Villa Río Negro" a Dr. Maradona, Prosperidad, Ghío y Mapic; en el CRR "Pedro Biolchi" a Puerto Vilelas y La Toma y en el CRR "Luis Fleitas" a Cacique Pelayo, Elba, y Puerto Vicentini.

\section{Consideraciones Finales}

Es importante conocer los patrones de distribución espacial de los determinantes socioeconómicos de la salud, ya que los mismos, favorecerán al diseño de políticas de salud que apunten a reducir las inequidades observadas. Pero para ello, se requiere la participación de todas las áreas del gobierno, como así también, de la comunidad. De esta manera, se priorizaran en mejorar aquellos determinantes que ejercen mayor control sobre la salud de las personas y se verán beneficiadas las comunidades más desfavorecidas.

Publicado en formato digital: Dras. Blanca Elizabeth Ponce, María Alejandra Fantín y Carola Leticia Bertone. ANÁLISIS ESPACIAL DE LOS DETERMINANTES SOCIOECONÓMICOS DE LA SALUD EN EL GRAN RESISTENCIA. Revista Geográfica Digital. IGUNNE. Facultad de Humanidades. UNNE. Año 11. № 22. Julio Diciembre. 2014. ISSN 1668-5180 Resistencia, Chaco.

En: http://hum.unne.edu.ar/revistas/geoweb/default.htm 
En este sentido, podemos decir que los determinantes socioeconómicos de la salud, que más contribuyen a la clasificación espacial corresponden a las dimensiones salud y habitacional, siendo sus principales variables: Hogares sin Agua dentro de la Vivienda y el Terreno; Población sin Obra Social; Hogares con Hacinamiento por Cuarto; Hogares con Piso de Tierra y Hogares con Viviendas Deficitarias.

Asimismo, debemos reconocer que los determinantes presenta un gradiente desfavorable en forma de anillos concéntricos en la medida que nos aproximamos a la periferia del Gran Resistencia.

Ahora bien, si consideramos a los cuatro CRR y la distribución de los barrios, podemos cerrar nuestro análisis diciendo que:

$>$ CRR "Villa Río Negro": en el encontramos cuatro situaciones posibles: en una mayor parte de su área de influencia, los determinantes socioeconómicos de la salud presentan una situación crítica muy alta, como ejemplo de ello tenemos al Barrio Santa Lucía y, en la medida que nos acercamos al casco céntrico de Resistencia, nos encontramos con: mejores situaciones (Villa Miranda Gallina), situación crítica baja, esto se da en la zona próxima al CRR (Villa Río Negro) y situación crítica intermedia (Villa La Isla y Villa El Bolsón).

> CRR "Villa Libertad": presenta una situación crítica baja de sus determinantes socioeconómicos; dentro de los barrios que se encuentran en su área de influencia podemos mencionar a Villa Libertad, Barrio P. Independencia; Villa Palermo I y Villa El Dorado. En las zonas próximas al centro de Resistencia encontramos mejores situaciones de los determinantes (Villa Centenario); mientras que hacia la periferia la situación es crítica intermedia (Barrio San Antonio).

> El CRR "Luis Fleitas": al igual que en los anteriores, en la zonas próximas al puesto sanitario, los determinantes socioeconómicos de la salud presentan una situación crítica baja (Fontana Centro, Barrio General Güemes, Barrio San Pantaleón, Barrio J. D. Perón, etc.) y, cuanto más nos alejamos de éste, nos encontramos con una situación crítica intermedia (Barrio Nueva Esperanza) y una situación crítica alta (Barrio AIPO).

EI CRR "Pedro Biolchi": sigue el mismo patrón, próximo a centro de salud tenemos una las mejores situaciones con respecto a los determinantes socioeconómicos de la salud (Villa Rossi) y, rodeando a ésta una situación crítica baja (Villa Emilia, Villa Fucksman).

Publicado en formato digital: Dras. Blanca Elizabeth Ponce, María Alejandra Fantín y Carola Leticia Bertone. ANÁLISIS ESPACIAL DE LOS DETERMINANTES SOCIOECONÓMICOS DE LA SALUD EN EL GRAN RESISTENCIA. Revista Geográfica Digital. IGUNNE. Facultad de Humanidades. UNNE. Año 11. № 22. Julio Diciembre. 2014. ISSN 1668-5180 Resistencia, Chaco.

En: http://hum.unne.edu.ar/revistas/geoweb/default.htm 
Revista Geográfica Digital. IGUNNE. Facultad de Humanidades. UNNE. Año 11. № 22.

$\mathrm{G}_{\mathrm{\theta}}$

\section{Mapa $\mathbf{N}^{\circ} 3$}

"Distribución espacial de los diferentes escenarios posibles. Gran Resistencia."

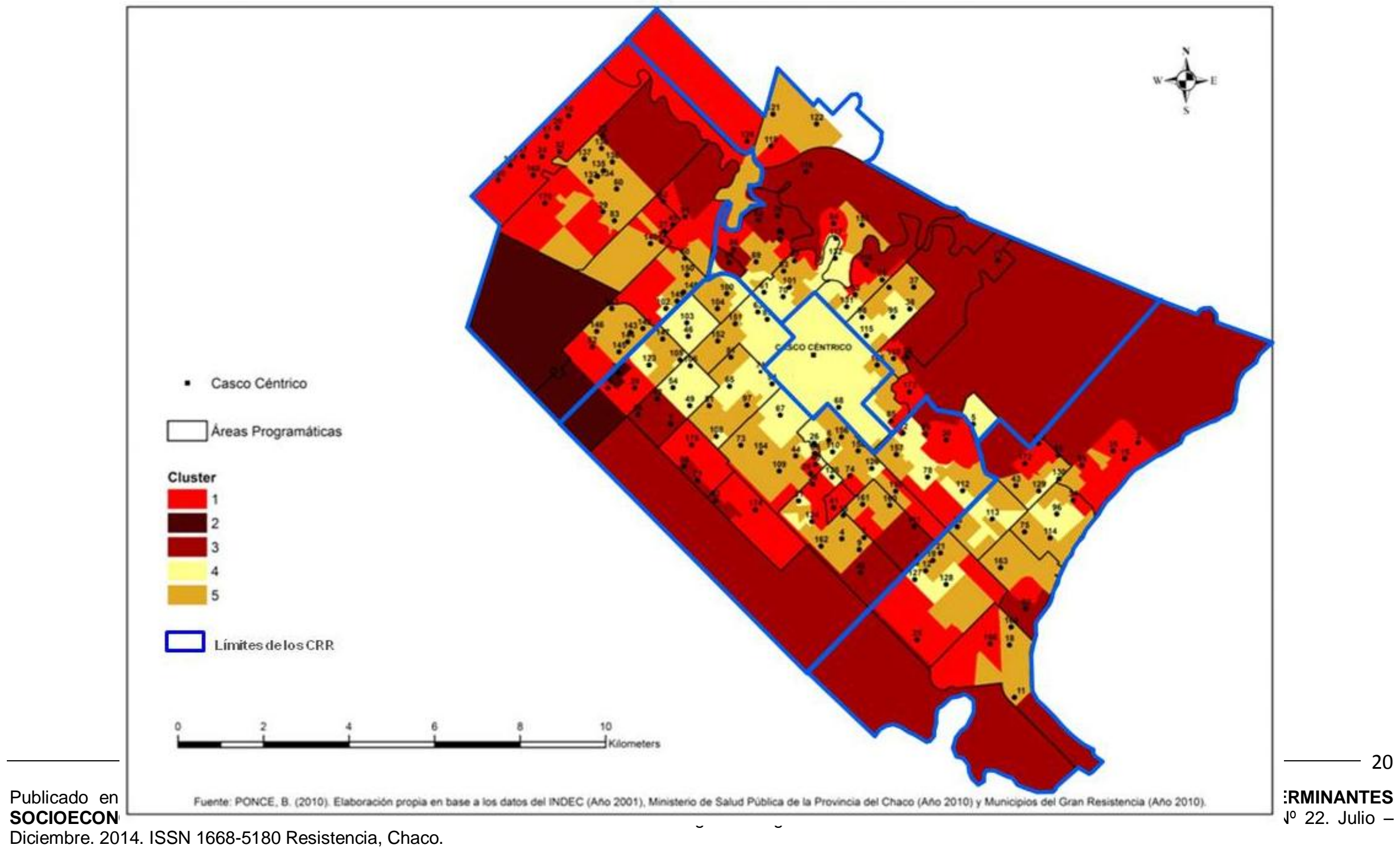

Diciembre. 2014. ISSN 1668-5180 Resistencia, Chaco.

En: http://hum.unne.edu.ar/revistas/geoweb/default.htm 
Revista Geográfica Digital. IGUNNE. Facultad de Humanidades. UNNE. Año 11. № 22. Julio - Diciembre 2014. ISSN 1668-5180 Resistencia, Chaco

\section{Tabla $\mathbf{N}^{\circ} 12$}

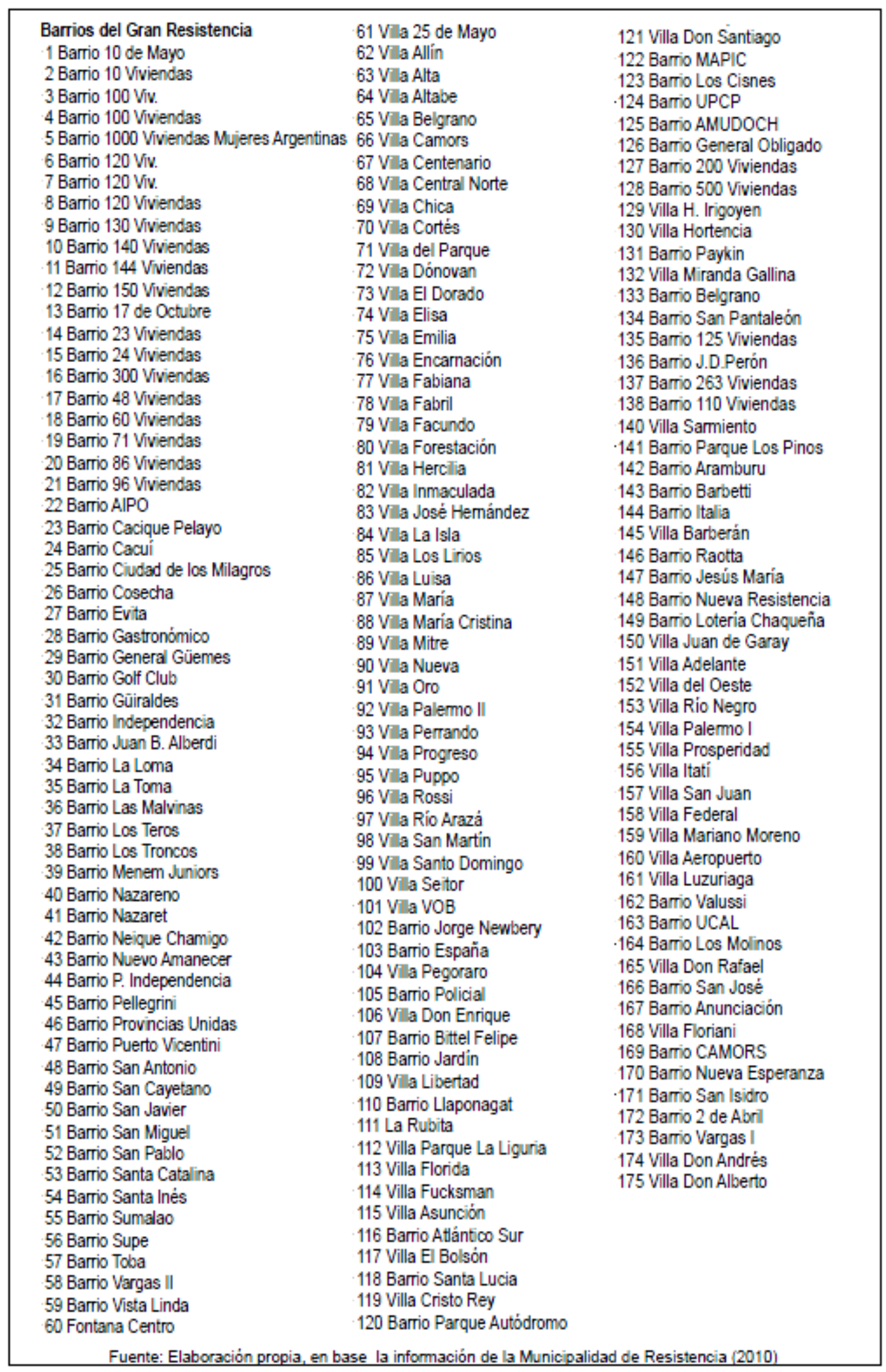

Publicado en formato digital: Dras. Blanca Elizabeth Ponce, María Alejandra Fantín y Carola Leticia Bertone. ANÁLISIS ESPACIAL DE LOS DETERMINANTES SOCIOECONÓMICOS DE LA SALUD EN EL GRAN RESISTENCIA. Revista Geográfica Digital. IGUNNE. Facultad de Humanidades. UNNE. Año 11. № 22. Julio Diciembre. 2014. ISSN 1668-5180 Resistencia, Chaco.

En: http://hum.unne.edu.ar/revistas/geoweb/default.htm 
Revista Geográfica Digital. IGUNNE. Facultad de Humanidades. UNNE. Año 11. № 22. Julio - Diciembre 2014. ISSN 1668-5180 Resistencia, Chaco

\section{Bibliografía}

Abalerón y otros. 1996. "La calidad de vida y vivienda precaria en clima frío: triangulación metodológica en Bariloche Argentina". Revista de Geografía, V. 13. Universidade Estadual Paulista/UNESP. Sao Paulo.

Acheson, D. 1998. "Independent inquiry into inequalities in elath". Report. The Stationery Office. London.

Aguilar, Mercedes. 2005. "Las defunciones por enfermedades infecciosas y parasitarias en relación con las condiciones sanitarias de la población argentina en el 2000. Una aproximación a la articulación agua-enfermedad". VIII Jornadas Argentinas de Estudios de Población de la Asociación de Estudios de Población de la Argentina. Tandil: Asociación de Estudios de Población de la Argentina.

Arriagada Luco, Camilo. 2003. "La dinámica demográfica y el sector habitacional en América Latina". Población y Desarrollo. Serie 33. CELADE- División de Población. Santiago de Chile, enero.

Borrell, Carme y Artazcoz, Lucía. 2008. "Las políticas para disminuir las desigualdades en salud". Gaceta Sanitaria. Vol. 22, № 5. Barcelona. 465-473.

Boroni, Gustavo y otros. 2002. "Geografía, calidad de vida y entropía. Aportes de la Teoría de la información para la construcción de un índice de calidad de vida a escala departamental (19912001)". En: Desigualdad y calidad de vida en la Argentina (1991-2001). Aportes empíricos y metodológicos. C. I. G. Facultad de Ciencias Humanas, UNCPBA. Buenos Aires.

Bruniard, Enrique D. y Alfredo Bolsi. 1975. "El proceso histórico de las características demográficas y socioeconómicas de la ciudad de Resistencia". Folia Histórica del Nordeste, Nㅜ 1. Instituto de Historia: Facultad de Humanidades, UNNE. Resistencia.

Burgess, Ernest W. 1929. "Urban areas". En: T. V. Smith y L. D. White (Eds). Chicago: An experiment in social science research. University of Chicago Press. Chicago, USA.

De la Fuente Fernández, Santiago. 2011. "Análisis de Conglomerados". Facultad de Ciencias Económicas y empresariales. Universidad Autónoma de Madrid. Madrid. URL disponible en: http://www.fuenterrebollo.com/Economicas/ECONOMETRIA/SEGMENTACION/CONGLOMERADOS/ conglomerados.pdf

Fantín, María Alejandra. 2008. "Población, Sociedad y Salud en la Frontera Argentino-Paraguaya". Asociación Paraguaya de Estudios de Población, Fondo de Población de las Naciones Unidas, IIGHICONICET, Resistencia.

Fantín, María Alejandra. 1999. "Condiciones socioeconómicas y salud en el Gran Resistencia a comienzo de la década de 1990". Córdoba: Centro de Estudios Avanzados, U. N. C. pp. 127.

Foschiatti de Dell 'Orto, Ana María. 1991. "El desarrollo urbano y las particularidades demográficas del Chaco y su capital entre 1960 y 1990". Demográfica № 4. Resistencia.

Frenz, Patricia. 2005. "Desafíos en salud pública de la Reforma, equidad y determinantes". Revista Chilena de Salud Pública. Tema de Actualidad; Vol 9 (2): 103- 110. URL disponible en:

http://www.revistasaludpublica.uchile.cl/index.php/RCSP/article/viewFile/20128/21293

Instituto Nacional de Estadísticas y Censos. (INDEC). 2001. "Censo Nacional de Población, Hogares y Vivienda de la Provincia del Chaco, 2001". INDEC. Buenos Aires.

Lalonde M.A. 1974. "New perspective on the health of Canadians". Department of National Health and Welfare. Ottawa, Canadá.

Manoiloff, Raúl Oscar. 1992. "Caracteres del movimiento natural de la población de Resistencia, Barranqueras, Puerto Vilelas y Fontana (Gran Resistencia) en 1980". Demográfica: Revista de Estudios de Población N 6, Editorial Grafos. Resistencia.

Meichtry Norma y Aníbal Mignone. 2001. "Movilidad territorial. Una contribución a partir de la población en asentamientos periféricos espontáneos en Resistencia, Chaco, en la década de 1990". En: VI Jornadas de la Asociación de Estudios de Población de la Argentina. Asociación de Estudios de Población de la Argentina (AEPA). Universidad Nacional del Comahue, Neuquén.

Organización Mundial de la Salud (OMS). 2011. "Cerrando la Brecha: La política de acción sobre los determinantes sociales de la salud. Todos por la Equidad". Documento de Trabajo. Conferencia mundial sobre los determinantes sociales de la salud. OMS. Río de Janeiro, Brasil.

Publicado en formato digital: Dras. Blanca Elizabeth Ponce, María Alejandra Fantín y Carola Leticia Bertone. ANÁLISIS ESPACIAL DE LOS DETERMINANTES SOCIOECONÓMICOS DE LA SALUD EN EL GRAN RESISTENCIA. Revista Geográfica Digital. IGUNNE. Facultad de Humanidades. UNNE. Año 11. № 22. Julio Diciembre. 2014. ISSN 1668-5180 Resistencia, Chaco.

En: http://hum.unne.edu.ar/revistas/geoweb/default.htm 
Organización Mundial de la Salud (OMS) y Fondo de las Naciones Unidas para la Infancia (UNICEF). 1978. Declaración de Alma Ata. Conferencia Internacional sobre Atención Primaria de la Salud. OMS. Serie Salud para todos $N^{\circ} 1$. Ginebra, Suiza. URL disponible en:

http://whqlibdoc.who.int/publications/9243541358.pdf

Picón Prado, Eduardo y otros. 2007. "Clasificación y segmentación. Post Hoc mediante el análisis de conglomerados". En: Métodos Cuantitativos en Geografía de la Salud. Serie-Publicaciones del PROEG No 2. Universidad Nacional del Luján. Departamento de Ciencias Sociales. Programa de Estudios Geográficos, Luján.

Rogeaux, O. (1993), "Maladies liées à l'eau: classification”. En: Développement et santé, nº 104.

Sabuda, Fernando. (2008). "Diferenciación sociocultural de los hogares. Aportes para el análisis territorial de la vulnerabilidad educativa en el Partido de General Pueyrredón". En Territorio y calidad de vida, una mirada desde la geografía local. Mar del Plata y Partido de General Pueyrredón. Edición de Patricia Lucero et al., 141-176. Mar del Plata: GESPyT / Eudem.

Valenzuela de Mari, Cristina. 1992. "Hábitat, vivienda y mortalidad infantil (Las relaciones espaciales entre el medio geográfico, las condiciones socioeconómicas y las variables demográficas en las provincias del Nordeste, en 1980.)". XII Encuentro de Geohistoria Regional, IIGHI. Resistencia.

\footnotetext{
${ }^{1}$ Conferencia Sanitaria Internacional, Nueva York, 19 de junio al 22 de julio de 1946, (Official Records of the World Health Organization, № 2, p. 100).

${ }^{2}$ La Conferencia Internacional sobre Atención Primaria de la Salud de Alma-Ata organizada por la OMS, OPS y UNICEF, fue realizada en Kazajistán, del 6 al 12 de septiembre de 1978. La síntesis de sus intenciones se expresa en la Declaración de Alma-Ata.
}

${ }^{3}$ Es el acrónimo de REcuperación de DATos para Áreas pequeñas por Microcomputador. Es una solución tecnológica desarrollada por el CELADE de la CEPAL (Naciones Unidas), para la caracterización y el análisis de los microdatos censales, a partir del procesamiento de los datos en línea, con la posibilidad de obtener tablas, gráficos y/o mapas.

${ }^{4}$ Programa estadístico informático. Originalmente fue creado como el acrónimo de Statistical Package for the Social Sciences. En la actualidad su nombre (IBM SPSS) no es acrónimo de nada.

${ }^{5}$ Cartalinx se utiliza para crear coberturas, que consisten en las definiciones de características espaciales en formato vector ial, y sus valores de atributos respectivos.

${ }^{6}$ Producido y comercializado por ESRI, bajo el nombre genérico ArcGIS se agrupan varias aplicaciones para la captura, edición, análisis, tratamiento, diseño, publicación e impresión de información geográfica.

${ }^{7}$ De acuerdo con la información censal del año 2010 la población del Gran Resistencia representa el 37\% del total provincial.

8 Los hospitales "Julio C. Perrando" y "Dr. Avelino Castelán" de Resistencia son establecimientos de referencia provincial. Ambos proyectan su área de influencia en términos generales sobre todo el Chaco, principalmente sobre el sector este, pero además se extiende hasta el sureste de la provincia de Formosa, noreste de la provincia de Santa Fe y en el noroeste de la provincia de Corrientes.

${ }^{5}$ Es la relación entre el número de hombres y de mujeres en una población dada. Se expresa como el número de varones por cada 100 mujeres.

${ }^{10}$ Estudios Terciarios: comprende los estudios que se realizan en instituciones de educación terciaria no universitaria, estatal es o privados, con planes de estudios aprobados por el Ministerio de Educación (de la nación o de las provincias); incluye los profesorados de nivel inicial, de adultos, de enseñanza especial (sordomudos, ciegos, sordos, etcétera) y educación física, historia, letras, etcétera. Comprende también especialidades no docentes, por ejemplo: especialización técnica industrial, periodismo, turismo, computación, bellas artes y la formación de oficiales de las fuerzas armadas. Estudios Universitarios: incluye los estudios que se realizan en universidades nacionales, provinciales o privadas. Comprende exclusivamente las carreras que otorgan títulos profesionales (abogado, agrimensor, fonoaudiólogo, ingeniero, profesor, etcétera) y las licenciaturas (en ciencias de la educación, letras, matemática, sistemas, etcétera). (INDEC, 2001)

${ }^{11}$ En general, se puede afirmar que la calidad de vida comprende, en primer término, la base material en la cual se desarrolla la vida; en segundo lugar, el ambiente natural y construido en el cual se desenvuelve el ser humano; y en última instancia, a todas las relaciones que devienen de las actividades realizadas, tanto el trabajo como otro tipo de relaciones sociopolíticas y culturales. (Sabuda, 2008)

${ }_{12}$ La "obra social" refiere a la cobertura de salud que obtienen las personas que trabajan y sus familiares mediante afiliación obligatoria, incluyendo a la cobertura legal que reciben las personas jubiladas o pensionadas. (INDEC, 2001)

${ }^{13}$ El hogar posee un sistema de suministro de agua dentro de los límites que ocupa el terreno pero no dispone de una red de tuberías para distribuirla hacia el interior de la vivienda. (INDEC, 2001)

${ }^{14} \mathrm{El} \mathrm{hogar}$ accede a un sistema de suministro de agua que se encuentra fuera de la vivienda y fuera de los límites que ocupa el terreno. (INDEC, 2001).

${ }^{15}$ Hace referencia a la disponibilidad de un artefacto instalado dentro del baño/letrina que se utiliza para la evacuación de excretas, que no tiene un sistema de descarga de agua para su limpieza; o no dispone de ningún artefacto para la eliminación de excretas (INDEC, 2001).

${ }^{16}$ Solamente el $43 \%$ de los hogares del Gran Resistencia (especialmente el casco céntrico y algunos barrios planificados) tiene acceso a la red cloacal, mientras el resto recurre a pozos ciegos para la descarga de los retretes o inodoros. Sin embargo, esto no puede tomarse como un indicador de deficiencia de la vivienda, ya que existen barrios donde la población posee buenos

Publicado en formato digital: Dras. Blanca Elizabeth Ponce, María Alejandra Fantín y Carola Leticia Bertone. ANÁLISIS ESPACIAL DE LOS DETERMINANTES SOCIOECONÓMICOS DE LA SALUD EN EL GRAN RESISTENCIA. Revista Geográfica Digital. IGUNNE. Facultad de Humanidades. UNNE. Año 11. № 22. Julio Diciembre. 2014. ISSN 1668-5180 Resistencia, Chaco.

En: http://hum.unne.edu.ar/revistas/geoweb/default.htm 
recursos económicos y, sin embargo, carecen de red cloacal. Dicha situación, responde a una falta planificación y mejoramiento de infraestructura por parte del gobierno provincial y no, a la falta de recursos económicos de sus habitantes.

${ }^{17}$ De acuerdo con informes del Ministerio de Salud Pública de la Provincia del Chaco, el brote de cólera de la década del ' 90 fue causado en gran parte por una deficiente disposición de las excretas.

${ }^{18}$ Los materiales predominantes de los componentes constitutivos de la vivienda (pisos, paredes y techos) se evalúan y categorizan con relación a su solidez, resistencia y capacidad de aislamiento térmico, hidrófugo y sonoro. Se incluye asimismo la presencia de determinados detalles de terminación: cielorraso, revoque exterior y cubierta del piso. La variable CALMAT I, considera a las viviendas que presentan materiales resistentes y sólidos en todos los componentes constitutivos (pisos, paredes y techos) e incorpora todos los elementos de aislación y terminación. (INDEC, 2001).

${ }^{19}$ Para la elaboración del indicador se consideraron viviendas deficitarias, a las casas tipo "b", los ranchos, casillas, pieza inquilinato, pieza de hotel o pensión, local no construido para habitación, vivienda móvil y en la calle.

${ }^{20}$ Consideramos a un hogar en condición de hacinamiento, cuando tienen más de tres personas por cuarto. (INDEC, 2001)

${ }^{21}$ Se considera dos elementos para la definición del material de las paredes exteriores: los muros que constituyen el contorno externo de la estructura de la vivienda y el revoque/revestimiento externo que es la cobertura que protege el material (ladrillos, bloques y mampostería en general) del lado de afuera de las paredes exteriores. Si no está revocada la totalidad de las paredes exteriores, se tiene en cuenta la situación que predomina. En el caso de que las paredes exteriores tuvieran ladrillo a la vista, se considera que tienen revoque/revestimiento externo. (INDEC, 2001)

${ }^{22}$ En relación con la salud se acostumbra a agruparlos según sus cualidades en: cerámica - baldosa - mosaico y cemento ladrillo por un lado y tierra por otro. El piso de tierra, además de ser un indicador de las pobres condiciones socioeconómicas de los hogares, representa un peligro para la salud, especialmente de los infantes, por la exposición a las condiciones de insalubridad. (Fantín, 1999).

${ }^{23}$ De acuerdo con la definición dada por el INDEC (2001), una persona es considerada desocupada cuando no teniendo ocupación en el momento de realizarse el censo, lo está buscando activamente.

${ }^{24}$ En este sentido, debemos establecer la diferencia que existe entre descuento jubilatorio y aporte jubilatorio. El primero de ellos hace referencia a las retenciones que la empresa u organismo realiza a sus trabajadores, dirigidas a pagar los aportes jubilatorios establecidos legalmente; mientras que el segundo, es realizado directamente y en su totalidad por el trabajador.

${ }^{25}$ El análisis de conglomerados posee algunos inconvenientes, ya que se trata de una técnica descriptiva, ateórica y no inferencial. No tiene bases estadísticas sobre las que deducir inferencias estadísticas para una población a partir de una muestra, es un método basado en criterios geométricos y se utiliza fundamentalmente como una técnica exploratoria, descriptiva pero no explicativa.

${ }^{26}$ Éstos a su vez se clasifican en: a) Asociativos o aglomerativos: se parte de tantos grupos como individuos y se van agrupando hasta llegar a tener todos los individuos en un solo grupo. b) Disociativos: se parte de un solo grupo que contenga a todos los individuos y se va separando hasta llegar a formar grupos individuales.

${ }^{27}$ Con el objeto de conseguir una mejor clasificación, se ha seleccionado la opción "iterar y clasificar", la cual emplea un proceso iterativo de reasignación de los casos al grupo cuyo centroide esté más cercano (los centros iniciales de los conglomerados se utilizan como criterio para una primera clasificación y, a partir de ahí, se van actualizando). Cabe aclarar que no se utilizó la opción "usar medias actualizadas", es decir que en esta investigación, los nuevos centros de los conglomerad os se calcularon después de la asignación de todos los casos.

${ }^{28}$ En esta investigación, su elección resulta de manejar un gran número de casos.

${ }^{29}$ Una de las reglas cartográficas explica que una escala cromática no puede estar integrada por más de cinco categorías, ya que el ojo humano no es capaz de distinguirlas. Si agregáramos una categoría más la interpretación se dificultaría.

30 Debe aclararse que las observaciones tipificadas se construyen restando a todos los datos la media y dividiendo por la desviación típica. La variable tipificada expresa el número de desviaciones típicas que cada observación dista de la media. Permite comparar posición relativa de datos de diferentes variables, puesto que la nueva variable, Z, es adimensional. La media de los datos tipificados es 0 . La desviación típica de los datos tipificados es 1.

${ }^{31}$ Cabe recordar que, el método K-medias utiliza la distancia euclídea para calcular las distancias, es decir la raíz cuadrada de la suma de los cuadrados de las diferencias entre los valores de los elementos.

${ }^{32}$ A pesar de los resultados obtenidos, hay que tener prudencia en su interpretación puesto que el propio programa advierte que este test únicamente debe utilizarse con una finalidad descriptiva, que ya los conglomerados han sido previamente elegidos para maximizar las diferencias entre los casos en diferentes conglomerados. En cualquier caso, su utilización facilita valorar la relevancia de las variables seleccionadas y comparar las diferentes agrupaciones.

Publicado en formato digital: Dras. Blanca Elizabeth Ponce, María Alejandra Fantín y Carola Leticia Bertone. ANÁLISIS ESPACIAL DE LOS DETERMINANTES SOCIOECONÓMICOS DE LA SALUD EN EL GRAN RESISTENCIA. Revista Geográfica Digital. IGUNNE. Facultad de Humanidades. UNNE. Año 11. № 22. Julio Diciembre. 2014. ISSN 1668-5180 Resistencia, Chaco.

En: http://hum.unne.edu.ar/revistas/geoweb/default.htm 